\title{
DESIRED COACHING BEHAVIOURS OF ELITE DIVERS DURING COMPETITON
}

\author{
Siobhan Henderson
}

\author{
A thesis \\ submitted in partial fulfilment \\ of the requirements for the degree of Master of Arts \\ in the Department of Kinesiology \& Physical Education \\ in the Faculty of Education \\ McGill University
}

August 21, 2020

(C) Siobhan Henderson 


\begin{abstract}
Competitions are often definitive moments for an athlete's career, and an athlete's success can be influenced by the knowledge and strategies of their coach. The purpose of the current study was to gain a better understanding of elite individual sport athletes' (i.e., divers) perspectives of their coaches' behaviours during competition, which included their desired coaching behaviours in this context. Semi-structured interviews were conducted with six Canadian divers on the national team. Interviews were transcribed verbatim, and a thematic analysis was used to organize data into themes and subthemes, as well as to provide a complete understanding of each experience (Sparkes \& Smith, 2014). Thematic analysis minimally organizes and describes the data collected in rich detail by identifying, analyzing, interpreting, and reporting patterns (Braun \& Clarke, 2013). The current analysis revealed three overarching themes from the data: background and characteristics, coach-athlete relationship, and coaching strategies and behaviours. First, background and characteristics included experiences and characteristics of athletes and coaches contributing to their behaviours and success. Second, coach-athlete relationship related to the positive and negative factors of the relationship influencing all facets of their partnership. Third, coaching strategies and behaviours involved strategies and behaviours used by coaches that influenced how their athletes coped with and performed during competition. Overall, the current results revealed that athletes emphasized closeness (i.e., trust) and co-orientation (i.e., understanding) as crucial elements of the coach-athlete relationship. Levels of understanding were found to depend in part on the effectiveness of coach feedback and instruction during competition which was valued by athletes to direct their attention, prevent doubt from settling in, and manage their emotions. Furthermore, athletes found it particularly challenging to deal with certain negative emotions including when they felt their coaches were frustrated, disappointed, or giving up on them. Finally, results revealed that athletes and coaches carefully developed and implemented individualized routines to deal with the pressure of competition. Findings of this study may contribute to coaches' understanding of athletes' coaching preferences in the context of diving competition, and thus provide suggestions for coaches to be more effective in this sporting context.
\end{abstract}




\section{Résumé}

Les compétitions sont souvent des moments décisifs dans la carrière d'un athlète. Le succès de ce dernier peut être influencé par les connaissances et les stratégies utilisées par l'entraîneur. Le but de cette étude était donc d'explorer les perceptions d'athlètes impliqués dans un sport individuel (plongeon) concernant les comportements de leur entraîneur dans le contexte de compétition, incluant les préférences des athlètes face aux comportements de leur entraîneur. Des entrevues semi-structurées ont été menées avec six plongeurs canadiens de l'équipe nationale. Les entrevues ont été transcrites mot à mot et une analyse thématique a été utilisée pour organiser les données en thèmes et sous-thèmes. Ce processus permet de développer une compréhension en profondeur de chaque expérience de l'individu (Sparkes et Smith, 2014). L'analyse thématique organise et décrit les données recueillies en détail en identifiant, analysant, interprétant et décrivant les tendances observées (Braun et Clarke, 2013). L'analyse actuelle a révélé trois thèmes généraux basés sur les données: antécédents et caractéristiques, relation entraîneur-athlète, et stratégies et comportements de l'entraîneur. Premièrement, le thème antécédents et caractéristiques comprenaient les expériences et les caractéristiques des athlètes et entraîneurs ayant contribué à former leurs comportements et succès. Deuxièmement, relation entraîneur-athlète est lié aux facteurs positifs et négatifs de la relation influençant toutes les facettes de leur partenariat. Troisièmement, stratégies et les comportements de l'entraîneur incluaient les stratégies et comportements des entraîneurs qui pouvaient influencer l'approche et la performance des athlètes en compétition. Dans l'ensemble, les résultats actuels ont révélé que les athlètes valorisaient une relation de confiance avec leur entraîneur où ce dernier faisait preuve de compréhension. Ces éléments ont été identifiés comme étant cruciaux pour développer une relation de qualité entre l'entraîneur et l'athlète pour un fonctionnement optimal. Les niveaux de compréhension dépendaient en partie de l'efficacité des commentaires et instructions des entraîneurs pendant la compétition. Ces instructions étaient appréciées par les athlètes considérant que ces derniers leur permettaient de diriger leur attention, éviter les sentiments de doute et de gérer leurs émotions. De plus, les athlètes ont trouvé particulièrement difficile de gérer certaines émotions négatives, y compris lorsqu'ils avaient l'impression que leur entraîneur était frustré, déçu ou qu'il les abandonnait. Enfin, les résultats ont révélé que les athlètes et les entraîneurs ont méticuleusement développé et mis en œuvre des routines individualisées leur permettant de gérer la pression de compétition. Les résultats de cette étude peuvent permettre aux entraîneurs de mieux comprendre les préférences de leurs athlètes reliés à leur comportements et stratégies utilisées dans le contexte de compétition en plongeon. De plus, cette étude fournie des suggestions pratiques pour que les entraîneurs deviennent plus efficaces dans ce contexte sportif. 


\section{Acknowledgments}

- My supervisor, Dr. Gordon Bloom for giving me the opportunity to pursue a Master's degree in the McGill Sport Psychology Lab and for all of the related opportunities along the way. Thank you for the continuous support and guidance throughout the entire process which has not only allowed me to grow academically and professionally, but also personally. Thank you for being considerate and understanding while helping me with the challenge of balancing sport and academics.

- My committee members, Dr. Jordan Koch and Dr. Lindsay Duncan. Thank you for the insightful input and support throughout this process. Your openness and willingness to engage in discussions to stimulate reflection was much appreciated.

- Mom and Dad, for the unconditional support. Your strength, resiliency, and work ethic you bring to your own lives inspire me on a daily basis. Thank you for believing in my strength to tackle challenges head on and always encouraging me to pursue my biggest aspirations. Thank you for teaching me to appreciate the little things and to allow humour to be part of the balanced perspective.

- Papa, for being a true example of humility and courage. I have always been in awe of your ability to connect with anyone and everyone. Your kindness has made a profound impression on me. You will forever be my hero.

- McGill Sport Psych Lab, current and former members: Danielle, Jordan, Finn, Aaron, Becca, Mishi, Lara, Mathieu, Pierre, Urq, Liam, Lea, Will, Jeff, Cherokee, and Marc. Thank you for all of your help, support, countless spike ball games, and laughs throughout. I am very fortunate and grateful to be part of such an exceptional group of individuals, colleagues, and friends. Thanks team for always having my back. 
- Diving Canada and the national team members who agreed to participate in this study. Thank you for taking your time to share your inspiring experiences, for being open, and willing to take part. Additionally, thank you to diving coach Aaron Dziver for your help in all facets of this project.

- Plongeon Quebec for providing me with the opportunities to pursue my passion and for going above and beyond to provide support to athletes of the province. I am proud and thankful to be a part of this community which has provided me with many opportunities to share my passion and combine my academic and sport background.

- Club de Plongeon CAMO, for welcoming me with open arms. Thank you to everyone involved for your outstanding implication and devotion in helping me and my fellow teammates to become the best athletes we are capable of. I am proud to represent this club.

- My coach, Stéphane Lapointe. Thank you for your outstanding dedication, passion, and support. More importantly, thank you for taking me under your wing and believing in my abilities. The energy that you bring to the pool every day and the challenges you give me push me out of my comfort zone at times, but make every session very rewarding. You manage to make hard work fun. Thank you.

- Isabelle Cloutier, for going out of your way to provide me with opportunities to grow as an athlete. Thank you for always findings silver linings and providing a valuable perspective. I know I can always go to you to get an honest opinion, good advice, and caring support.

- My CAMO family: Élo, Olivia, Mélo, Simone, Lysanne, Peter. Each and every one of you inspire me to be better and wouldn't want to share the highs and lows in diving and 
life with anyone else. Thank you for putting a smile on my face every single day at training, for your support, and understanding.

- Club de Plongeon Agami, for playing an integral part in fueling my passion for the sport and shaping my journey as an athlete, coach, and individual. Thank you for being my second family for 13 years. The sense of community experienced was like no other.

- Nicholas Lachance, for believing in me from the start, inspiring me to dare to pursue my dreams, and teaching me to believe in myself. Thank you for making diving more than just a sport but an area where many life lessons can be learned.

- Aurée, Mims, and Steph, for being my rocks, sisters, and for keeping me grounded at all times. Thank you for always being there. 


\section{Table of Contents}

Abstract . . . . . . . . . . . . . . . . ii

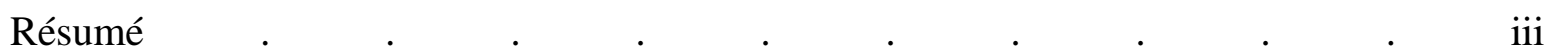

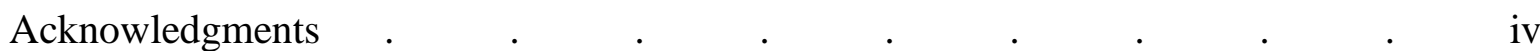

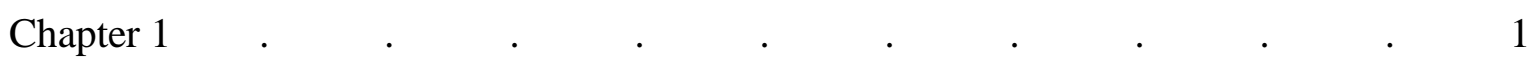

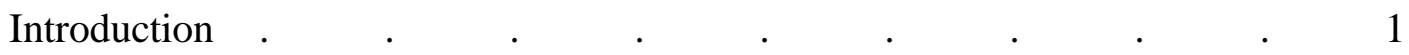

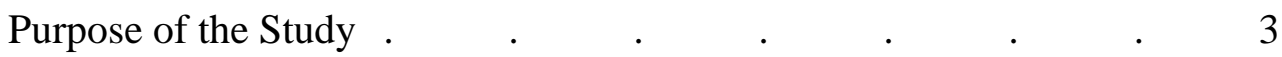

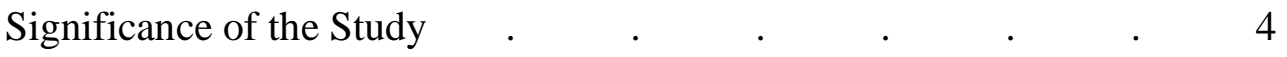

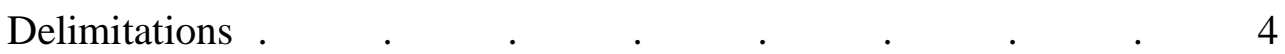

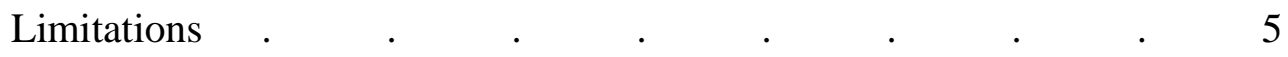

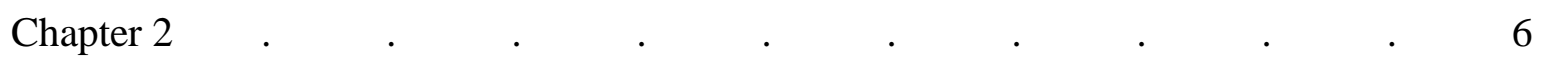

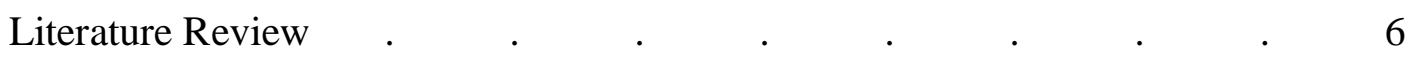

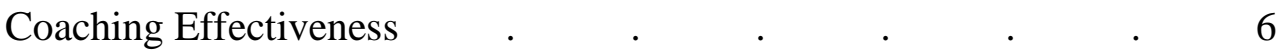

Coaches' Knowledge . $\quad . \quad$. $\quad . \quad$. $\quad . \quad 66$

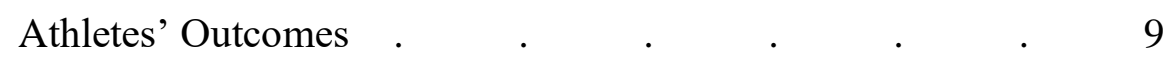

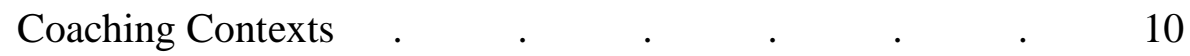

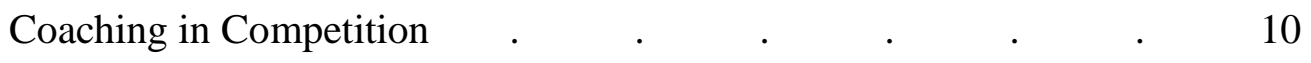

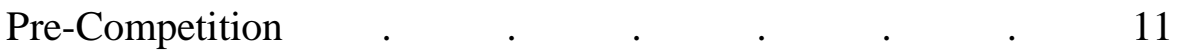

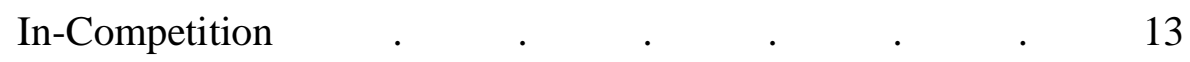

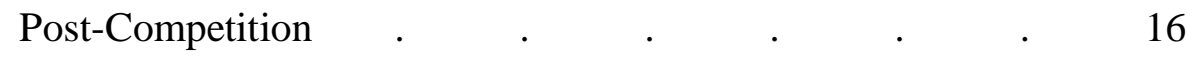

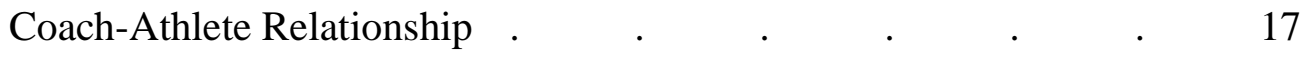

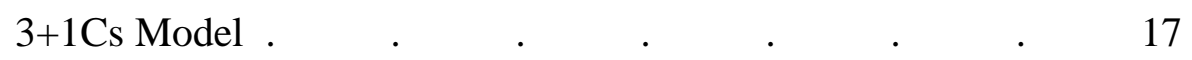

Factors Influencing the Coach-Athlete Relationship . $\quad$. 19 


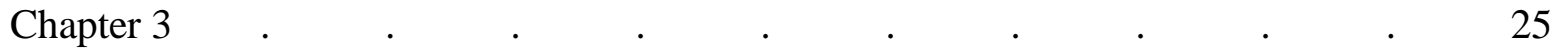

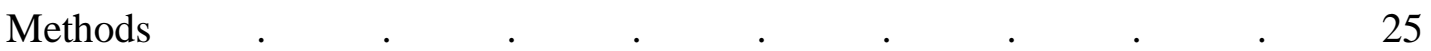

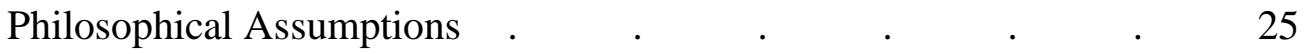

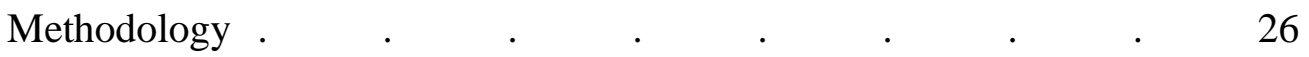

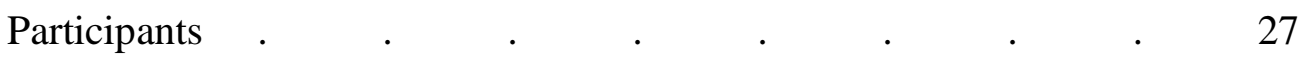

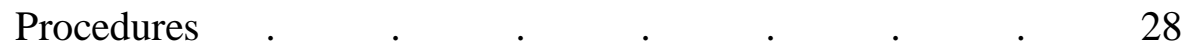

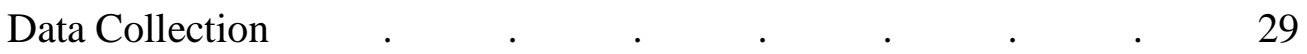

The Interviewer Biography $\quad . \quad$. $\quad$. $\quad$. $\quad$. 30

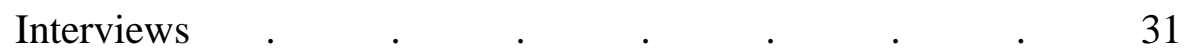

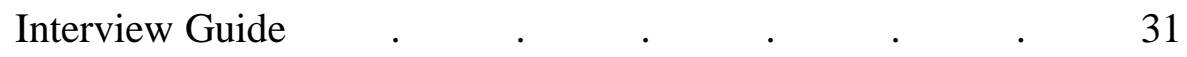

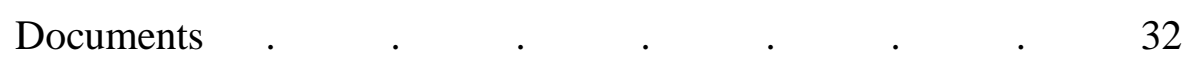

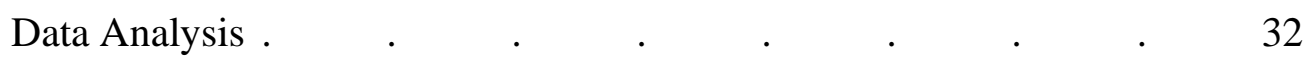

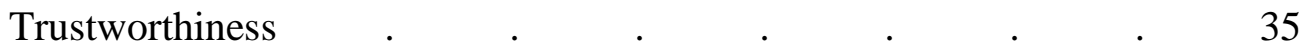

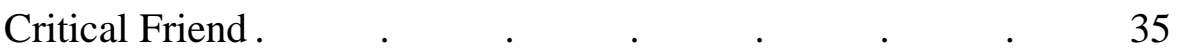

Substantive Width and Contribution . $\quad$. $\quad$. $\quad$. 36

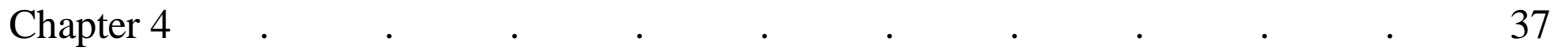

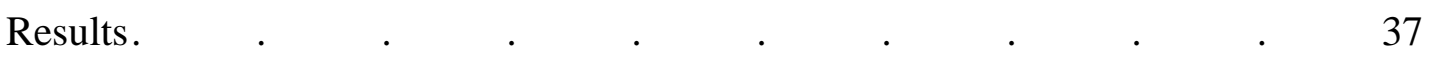

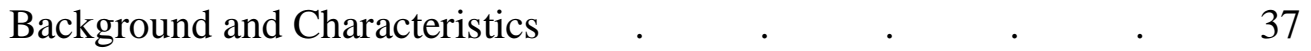

Athlete Experiences and Characteristics _ . . . $\quad$. 37

Coach Experiences and Characteristics. $\quad . \quad$. $\quad . \quad 39$

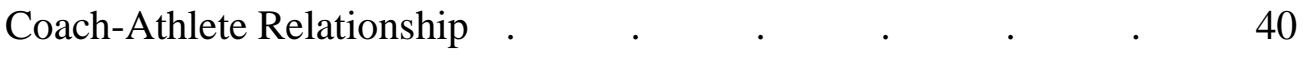

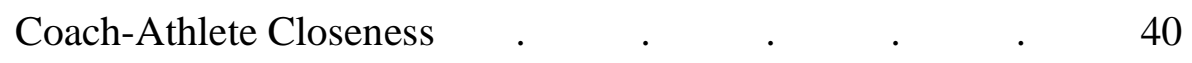

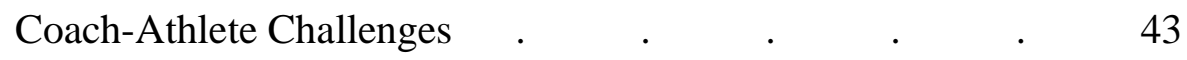


Coaching Strategies and Behaviours . $\quad . \quad$. $\quad$. $\quad$. $\quad$. 45

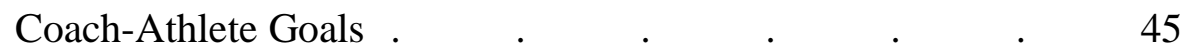

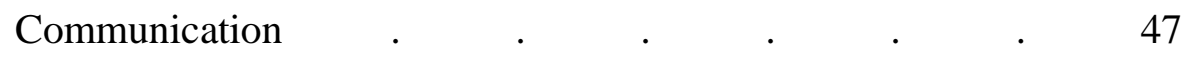

Coach Influence on Athlete Readiness $\quad$. $\quad$. $\quad$. $\quad 49$

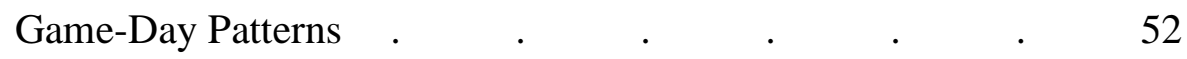

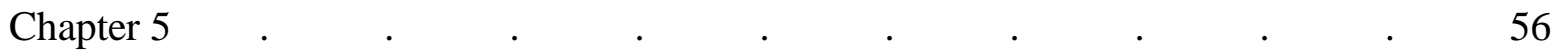

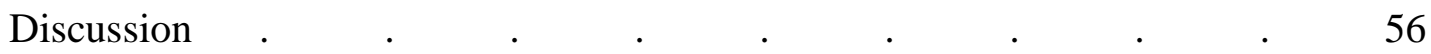

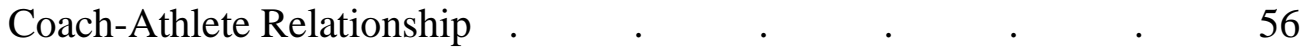

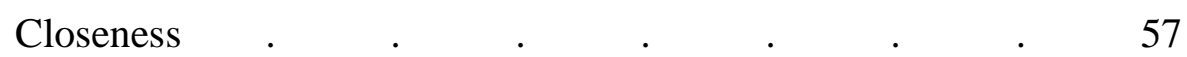

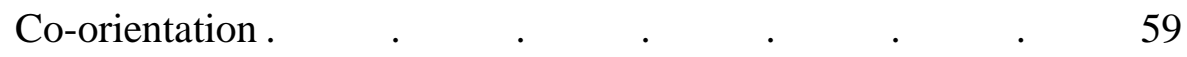

Coaching Strategies and Behaviours . $\quad . \quad \ldots \quad$. $\quad . \quad 63$

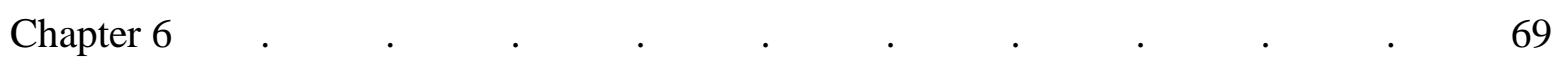

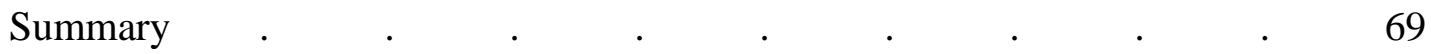

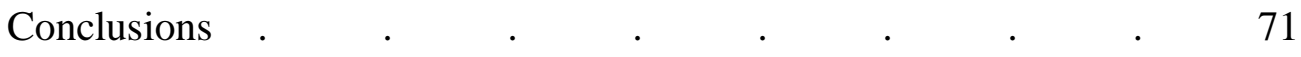

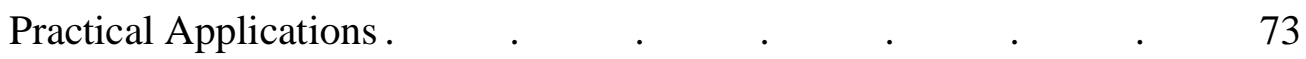

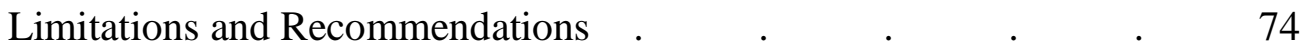

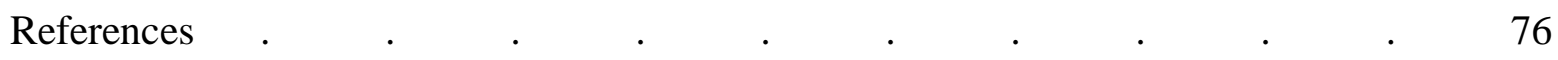

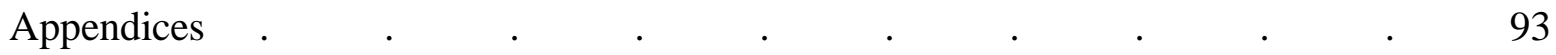

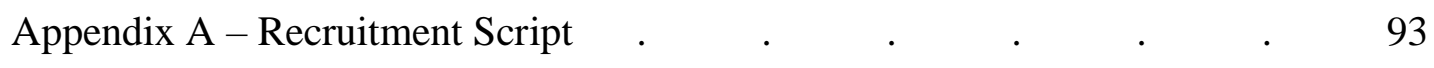

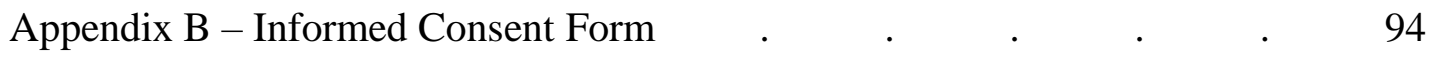

Appendix C - Semi-Structured Interview Guide $\quad . \quad$. $\quad . \quad$. 95

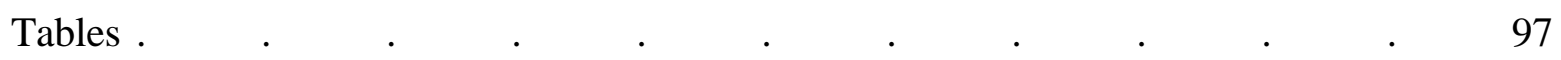

Table 1 - Codes, themes, and overarching themes from data analysis $\quad$. $\quad 97$ 
Introduction 1

\section{Chapter 1}

\section{Introduction}

An effective coach-athlete relationship has positively impacted athlete and team performance outcomes and is considered a central element of success in a high-performance sport environment (Jowett, 2017; Jowett \& Shanmugam, 2016; Mallet \& Lara-Bercial, 2016). The legendary swim coach James 'Doc' Cousilman was renowned for having very strong relationships with his athletes (Kimiecik \& Gould, 1987). His 42-year career included coaching the 1976 USA Olympic men's swim team to 12 out of a possible 13 gold medals. Cousilman recognized the needs of each athlete and took part in the goal setting process which was highly individualized, flexible, realistic, and based on the athlete's abilities (Kimiecik \& Gould, 1987). Furthermore, Counsilman was knowledgeable of his athletes' feelings and mental states prior to a swim meet and knew how to respond to the entire team and to each athlete individually (Kimiecik \& Gould, 1987). Cousilman was known for treating his athletes with respect and dignity while fostering their sense of autonomy (Kimiecik \& Gould, 1987). Taken together, Counsilman's success at building and maintaining strong relationships with his athletes may have partly contributed to the success in which his athletes performed at competitions.

In particular, research on the coach-athlete relationship has revealed differences between athletes in team and individual sports (e.g., Baker, Yardley, \& Côté, 2003; Jowett, Paull, \& Pensgaard, 2005). Jowett and Lavallee (2007) described the coach-athlete relationship as a dynamic interrelation between a coach and athlete's emotions, behaviours, and cognitions. According to Jowett and colleagues, the interdependence between these three variables forms the premise of the $3+1 \mathrm{Cs}$ (closeness, commitment, complementarity, and co-orientation) conceptualization of this relationship that has been used to study the coach-athlete relationship 
(Jowett \& Cockerill, 2003; Jowett \& Meek, 2000). More specifically, athletes in individual sports have experienced higher levels of closeness and commitment to their coach than athletes in team sports (Rhind, Jowett, \& Yang, 2012). This may be due to increased opportunities that individual sport coaches have to interact with their athletes on a one-on-one basis compared to coaches of team sport athletes who may work more with the athletes as part of a group (Rhind et al., 2012; Salminen \& Liukkonen, 1996). Moreover, if the quality of the relationship is compromised through negative closeness (distrust), dis-orientation (incongruent goals) and noncomplementarity transactions (power struggles), athletes will experience stress and could be distracted (Gould, Guinan, Greenleaf, Medbery, \& Peterson, 1999; Jowett \& Meek, 2000).

The context of competition is one place where the behaviours of the coach have the potential to influence athletes' performance and success (e.g., Allain, Bloom, \& Gilbert, 2018; Bloom, Falcão, \& Caron, 2014; Côté \& Gilbert, 2009; Gould, Greenleaf, Guinan, \& Chung, 2002; Mallett, 2005, 2010; Olusoga, Maynard, Hays, \& Butt, 2012; Vallée \& Bloom, 2005). As such, research has found that coaches play an active role in competition by implementing the strategies they have taught their athletes in practice in both team (Bloom, 1996; Bloom \& Salmela, 2000) and individual (Côté, Salmela, \& Russell, 1995; Halperin, Chapman, Martin, Abbiss, \& Wulf, 2016) sport settings. In fact, having well developed routines is an important coaching behaviour when interacting with athletes during competition (Allain et al., 2018; Côté et al., 1995), as is effective communication skills (Allain et al., 2018; Bloom, 1996; Bloom \& Salmela, 2000; Halperin et al., 2016; Smith \& Cushion, 2006). In fact, having the ability to communicate effectively highly depends on the coach's knowledge of factors related to the competitive event, including the emotional states of the athletes (Allain et al., 2018; Bloom, 1996; Bloom \& Salmela, 2000; Debanne \& Fontayne, 2009; Donoso-Morales, Bloom, \& Caron, 
2017a; Gilbert \& Côté, 2013; Gilbert, Trudel, \& Haughian, 1999; Lyle, 2010). Consequently, coaches adjust their approach to provide the appropriate type of feedback at the correct times in specific situations when interacting with athletes during competition (Smith \& Cushion, 2006; Halperin et al., 2016). Although having the ability to read the emotional states and moods of athletes is essential for coaches, their own emotional states are also a critical component of a coach's leadership style that can potentially influence player performance (Bloom \& Salmela, 2000; Donoso-Morales et al., 2017a; Olusoga et al., 2012; Wrisberg, 1990). However, to date, the majority of research on the importance of coaches in competition has focused on team sports (Allain et al., 2018; Bloom, Durand-Bush, \& Salmela, 1997; Gould et al., 1999; Greenleaf, Gould, \& Dieffenbach, 2001; Stein, Bloom, \& Sabiston, 2012). Given that various coaching differences have been identified between team and individual sports (Rhind et al., 2012; Salminen \& Liukkonen, 1996), one cannot always extrapolate all of the information obtained from team sport to individual sport contexts.

\section{Purpose of the Study}

The purpose of the study was to gain a better understanding of elite individual sport athletes' (i.e., divers) perspectives of their coaches' behaviours during competition, which included their desired coaching behaviours in this context. The purpose of this study was guided by the following questions:

1. How do divers perceive the role and influence of the coach in the context of competition?

2. What are divers' desired coaching behaviours in the context of competition?

3. What and how much information do divers want from their coaches between trials during competition? 
4. From the perspective of the athlete, in what ways does the quality of the coach-athlete relationship impact the interactions that take place between coaches and athletes between trials during competition?

\section{Significance of the Study}

Coaching elite sport is a highly demanding profession that involves operating within the constraints of a dynamic, complex, and pressurised environment (Thelwell, Wagstaff, Rayner, Chapman, \& Barker, 2017). A coach's continued employment is likely influenced by successful performance outcomes (Fletcher \& Scott, 2010). Therefore, coaches work under tremendous pressure while training and motivating their athletes to achieve great success (Olusoga et al., 2012). Coaches have highlighted the need to consider how their own emotions and behaviours can impact their relationships with athletes, as well as athlete performance during important competitions (Donoso-Morales et al., 2017a). Better understanding preferred coaching behaviours during competition from experienced divers will help diving coaches better understand how their behaviours in the context of competition correspond to the needs of their athletes. In turn, coaches' understanding of divers' coaching preferences in the context of competition may enable them to become more effective in this context, which may also positively influence athlete satisfaction and performance.

\section{Delimitations}

The following delimitations have been identified for the current study:

1. Participants will be currently competing or recently retired (within the past three years) in diving where interactions with the coach occur between trials during competition.

2. Participants will have a minimum of 5 years of experience competing at the 
international level with a minimum of one participation at a World Championship or Olympic Games.

3. Participants will be either male or female athletes over the age of 18 .

\section{Limitations}

Based on the delimitations of this study, the following limitations have been identified:

1. The results may only be applicable to coaches of elite athletes.

2. The results may only be applicable to athletes involved in individual sports of similar structure in competition.

3. The results are only representative of the perceptions of athletes and not those of the coaches.

4. Results are limited by the athletes' abilities to recall their experiences. 


\section{Chapter 2}

\section{Literature Review}

The chapter will consist of three main sections. The first section will address the topic of coaching effectiveness. The second section will focus on coaches' behaviours and interactions with athletes in competition. Finally, the third section will outline the conceptualization of the coach-athlete relationship and factors influencing the quality of this relationship.

\section{Coaching Effectiveness}

Côté and Gilbert (2009) proposed a definition of coaching effectiveness based on a review of the coaching, teaching, athlete development, and positive psychology literature. According to their definition, coaching effectiveness is "the consistent application of integrated professional, interpersonal, and intrapersonal knowledge to improve athletes' competence, confidence, connection, and character in specific coaching contexts" (Côté \& Gilbert, 2009, p. 316). A closer look at this definition highlights three major components that include coaches' knowledge, athletes' outcomes, and coaching contexts. The next section will provide a more detailed explanation of the components that form this definition.

Coaches' knowledge. Based on Collinson's (1996) model of knowledge content for expert coaches, Côté and Gilbert (2009) defined coach knowledge as being comprised of three main types that include professional knowledge, interpersonal knowledge, and intrapersonal knowledge. This section will expand on each type of knowledge.

First, professional knowledge encompasses the large body of specialized knowledge required to be a coach (Gilbert \& Côté, 2013). This includes declarative knowledge in the sport sciences, sport specific knowledge, pedagogical knowledge related to teaching sport skills, and procedural knowledge (Abraham, Collins, \& Martindale, 2006). Declarative knowledge refers to 
the set of facts about a certain skill and may include coaches' knowledge about tactics and training techniques (Nash \& Collins, 2006). This type of knowledge varies widely across sport settings considering the specificity of coaches' knowledge that is required for each sport (Gilbert \& Côté, 2013). However, some overlap in declarative knowledge may exist between sports when it comes to general principles of strength and conditioning, for example. Procedural knowledge refers to the steps or activities required to perform a skill (Anderson, 1982), and has been linked to their decision-making ability (Lyle, 2010). This refers to a coach's ability to read a situation and formulate a response (Lyle, 2010). As such, coaches must consider multiple factors when making decisions, especially in the context of competition. For example, youth ice-hockey coaches relied on both contextual factors about the game, as well as the personal characteristics of their players to make decisions (Gilbert, Trudel, \& Haughian, 1999). Therefore, coaches must have the ability to interpret situations during the game and respond based on previous and acquired knowledge to help athletes reach optimal performance. Additionally, procedural knowledge may also refer to skills that include planning, predicting, intuitive decision making, communicating, automaticity, observational analysis, problem-solving, self-monitoring, and perception (Schempp \& McCullick, 2010).

Second, interpersonal knowledge involves creating and maintaining relationships with their athletes, assistant coaches, parents, and other professionals (Gilbert \& Côté, 2013; Jowett, 2007). Coach-athlete interactions have been conceptualized as multidirectional which suggests that coaching is a complex, reciprocally influential process based on systems of social interactions (Cushion, Armour, \& Jones, 2006; Jowett, 2007). Lorimer and Jowett (2012) advocate that communication and understanding are key elements in relationships between coaches and athletes. Coaches demonstrate understanding when they are able to successfully 
identify and recognize the emotions experienced by their athletes. This enables coaches to use emotions to manage their relationships with others and regulate behaviours (Gilbert \& Côté, 2013). Considering the role emotions play in the management of coaches' relationships with others, emotional intelligence has been suggested as a model to frame interpersonal knowledge (Chan \& Mallet, 2011; Mayer \& Salovey, 1997). Emotional intelligence includes identifying, using, understanding, and managing emotions (Mayer \& Salovey, 1997). Developing this skill may enable coaches to communicate more effectively, prevent conflict, and help deal with athletes who are anxious or lack confidence (Gilbert \& Côté, 2013). Emotional intelligence describes essential competencies for coaches to develop interpersonal knowledge to become effective (Gilbert \& Côté, 2013). Continuously developing interpersonal knowledge enables coaches to communicate effectively and in an appropriate manner with the athletes and other individuals involved.

A third type of knowledge is intrapersonal which refers to the individual's understanding of the self and their ability for introspection and reflection (Gilbert \& Côté, 2013). It has also been referred to as self-awareness (Gilbert \& Côté, 2013). The development of intrapersonal knowledge comes from one's ability to translate experience into knowledge and skills (Gilbert \& Trudel, 2004). This can be done by engaging in reflection (Gilbert \& Côté, 2013). Based on Schön's (1983) theory of reflection, coach reflection includes reflection-in-action, reflection-onaction, and retrospective reflection-on-action (Schön, 1983). First, reflection-in-action occurs when coaches consciously engage in reflective conversation while coaching as an event is occurring during a competition or training session (Schön, 1983). As such, male professional youth soccer coaches were found to intentionally engage in moments of silence during which they engaged in multiple cognitive processes (Smith \& Cushion, 2006). During these moments, 
coaches reflected on tactical strategies as well as team and individual player performance (Smith \& Cushion, 2006). Therefore, this provides an example of coaches who use silent monitoring as a coaching strategy that allows them to reflect upon the events of the game and intervene accordingly. Second, reflection-on-action occurs when the coach engages in a reflective conversation after an event has occurred but while there is still an opportunity to apply potential solutions to resolve the event (Schön, 1983). Finally, restrospective reflection-on-action occurs when a coach engages in reflective conversation but long after the event has taken place (Schön, 1983). Although coach education programs have typically focused on developing coaches' professional knowledge, learning to integrate the three types of knowledge into one's practice is crucial to become an effective and expert coach (Gilbert \& Côté, 2013).

Athletes' outcomes. It has been suggested that desirable athlete outcomes arise as a result of effective coaching practices (Côté \& Gilbert, 2009). Côté and Gilbert (2009) used a specific framework that conceptualizes the desired athlete outcomes. Specifically, the 4 C's (Competence, Confidence, Connection, Character/Caring) are ideal outcomes that should emerge from the interactions of coaches and athletes in any sport environment. First, competence is the individual's perceptions of their abilities in sport-specific technical and tactical skills, performance skills, improved health and fitness, and healthy training habits. Second, confidence is the degree of certainty individuals possess about their ability to be successful (Feltz \& Chase, 1998). It is an internal sense of overall positive self-worth and self-efficacy (Côté, Bruner, Strachan, Erickson, Fraser-Thomas, 2010). Third, connection refers to the positive bonds and social relationships that athletes form with people inside and outside of sport (e.g. coach, peers, family members) (Côté et al., 2010). Finally, character and caring refers to moral development, sportsmanship, integrity, empathy, and responsibility (Côté et al., 2010; Côté \& Gilbert, 2009). 
Although effective coaches require extensive knowledge to successfully develop athletes' outcomes, the nature of the knowledge required varies tremendously based on the context in which the outcomes are developed.

Coaching contexts. The coaching effectiveness definition also includes the sport context or settings in which coaches operate to achieve athlete outcomes. This is an important element for coaches to consider as it will determine the knowledge and skills that are appropriate to apply in a given sport setting (Lyle, 2002). Lyle (2002) specified two contexts based on the levels of competition and included participation and performance coaching. The contexts were unique and distinct from the other based on the objectives related to sport involvement. The objectives of participation coaching involve short-term goals, enjoyment, and health-related outcomes where the emphasis is less demanding and intense (Côté \& Gilbert, 2009). On the other hand, performance coaching requires an intense commitment to a program in preparation for competition. Therefore, an effective coach must have the ability to properly tailor a training program according to the needs and objectives of the athletes as defined by the specific coaching context.

\section{Coaching in Competition}

Competitions are often definitive moments for an athlete's career, and an athlete's success can be influenced by the knowledge and strategies of their coach (e.g., Allain, Bloom, \& Gilbert, 2018; Bloom, Durand-Bush, \& Salmela, 1997; Bloom, Falcão, \& Caron, 2014; Côté \& Gilbert, 2009; Gould, Greenleaf, Guinan, \& Chung, 2002; Mallett, 2005, 2010; Olusoga, Maynard, Hays \& Butt, 2012; Vallée \& Bloom, 2005). In an attempt to better understand the process of coaching, the Coaching Model (CM; Côté, Salmela, Trudel, Baria, \& Russell, 1995) involves the application of knowledge to help athletes reach an optimal performance level based 
on their potential. There are three main phases involved in the competition component of the CM: pre-competition, in-competition, and post-competition (Côté et al., 1995). The following sections will provide a more in-depth explanation of each competition phase.

Pre-competition. Effective preparation is a crucial component of the pre-competition phase (Bloom, 1996; Bloom \& Salmela, 2000; Olusoga et al., 2012). For example, Bloom and Salmela (2000) interviewed some of Canada's most successful team sport coaches to better understand their characteristics, knowledge, and strategies that allowed them to effectively carry out their objectives. A common belief shared by coaches was that the outcome of the competition was a direct result of the preparation and organization that took place prior to the competition (Bloom \& Salmela, 2000). As such, coaches assisted in the organization of different activities to prepare their athletes for competition prior to arriving at the competition location (Bloom \& Salmela, 2000). For example, coaches organized mandatory team activities such as pre-game meals that were designed to increase the closeness of the team (Bloom, 1996). Similarly, coaches of an individual sport such as gymnastics emphasized the importance of holding meetings with their athletes the night before a competition with the intention of helping their athletes manage distractions (Côté, Salmela, \& Russell, 1995). Furthermore, coaches played a role in developing routines for their athletes. For example, coaches developed a specific schedule for their athletes the day before the competition that was replicated the day of the competition (Côté et al., 1995). Although coaches are invested in the preparation of their athletes, they were also concerned with their own personal preparation prior to the competition. As such, coaches highlighted the need to get enough rest before a game, as well as going for a morning jog or reading books to help deal with anxiety levels and the nerves prior to a game (Bloom, 1996; Bloom \& Salmela, 2000). Similarly, British Olympic coaches also discussed the value of engaging in healthy lifestyle 
behaviours such as keeping physically fit and conserving energy by limiting distractions in their personal lives to be well prepared for the Olympics (Olusoga et al., 2012). They also discussed the value in clearly articulating goals as well as the roles and responsibilities of the coach for the athletes to know what to expect from their coaches during the event (Olusoga et al., 2012). Athletes also mentioned that their coach's actions or personality did not change regardless of the importance of each match (Becker, 2009).

Although the preparation that takes place prior to arriving at the event location is important for both athletes and coaches, the preparation also continues once they arrived at the competition site. Coaches appear to play a role in helping their athletes prepare by engaging in different on-site behaviours that were designed to enhance both the physical and mental preparation of their athletes (Bloom, 1996). For example, coaches identified specific times and locations of the events that would occur during the day including an imposed set of drills that was part of the pre-game routine. Coaches also allocated time for individual mental preparation during the day (Bloom, 1996). Furthermore, coaches also carefully prepared the team meeting, the pre-game warm up, and the pre-game talk for their athletes (Bloom, 1996; Bloom et al., 1997; Bloom \& Salmela, 2000). During the team meeting, coaches relayed a game plan that was based on what they worked on during previous training sessions (Bloom, 1996; Bloom et al., 1997). The pre-game warm-up was well organized, structured, and cohesive and allowed the coaches time to scout the opposition (Bloom, 1996; Bloom et al., 1997). Finally, the pre-game speech was designed to help athletes achieve optimal levels of arousal (Bloom et al., 1997). The content of the pre-game speech can potentially influence athletes' feelings of efficacy immediately prior to competition (Vargas \& Short, 2011). As such, Vargas-Tonsing and Guan (2007) found that athletes preferred more informational content when facing either a known or 
unknown opponent and athletes preferred the most emotional content prior to a championship game. Furthermore, in the context of an individual sport, expert gymnastics coaches provided minimal technical information immediately before an event (Côté et al., 1995). As such, coaches specifically tried to keep from over coaching during this time to keep their athletes loose and confident (Côté et al., 1995). Therefore, the effectiveness of the coach's message before the event is specific to the types of sport. Coaches also must be well prepared and be able to adapt to the situation when delivering their message.

In-competition. During the game, expert team sport coaches have discussed the actions and strategies used to make effective adjustments during the game related to substitutions, timeouts, interactions with officials, intermissions, and athlete playing time (Bloom, 1996). When it comes to calling time outs, Duke and Corlett (1992) administered questionnaires to University women's basketball coaches to understand what influenced their decisions. Among the most frequently reported factors were their perceptions of the physical state of their athletes and the strategic responses to offensive or defensive events during the game (Duke \& Corlett, 1992). Additionally, Gilbert and colleagues (1999) investigated the factors ice hockey coaches considered when making interactive decisions during games. They found that coaches relied on contextual cues (e.g., score of the game, time restraints, face-off location, team performance, etc.) and knowledge of their players (e.g., skills of players, physical and psychological attributes) (Gilbert et al., 1999). Therefore, the coaches' level of expertise and perceptions allows them to make appropriate calls at the right times. It also appears to be crucial for coaches to have confidence in their decisions (Olusoga et al., 2012).

Relying on contextual factors of the game as well as player characteristics has also been shown to be relevant during intermissions (Allain et al., 2018). As such, highly experienced and 
successful University ice hockey coaches have highlighted the challenge of effectively managing their intermission time (Allain et al., 2018). These experienced coaches developed well-planned routines as a strategy to make the most of their time. For example, immediately after the end of the period, coaches met with their staff for approximately five minutes to analyze the game and create a game plan. Coaches highly valued the expertise and input of their support staff (Bloom, 1996; Olusoga et al., 2012). This time also provided coaches with the opportunity to prepare mentally and emotionally before talking to the players. After consulting with their staff, coaches addressed the team for an average of 3.5 minutes, ranging from 1.5 to 6 minutes. During this time, coaches provided three key points that focused on what the team needed to do to play to their full potential. Furthermore, coaches analyzed players' mood, body language, and interactions to adjust their approach. As such, coaches would either give them an energy boost or settle them down to ensure that they maintained their composure. Therefore, not only was the content of the message important, but also the delivery. Coaches adjusted their tone of voice and body language depending on their interpretation of competition situational factors. They also stressed the importance of positive emotions during the intermission (Allain et al., 2018).

Therefore, it appears that the coach's content and delivery of the message during the intermission is crucial to provide guidance for their athletes to perform optimally.

Considering the coach's responsibility to make effective decisions during a game and the extent to which they can influence athletes during this time, it becomes crucial to consider elements of their leadership style that can contribute to their effectiveness. First, it is crucial for coaches to have the ability to control their emotions (Bloom \& Salmela, 2000). As such, DonosoMorales, Bloom, and Caron (2017a) investigated some of Canada's most successful University team sport coaches and found that their emotional control during national championships was an 
important component for enhancing team success. Some of the coaches felt as though they mismanaged their emotions in their first appearance at a national championship, which in turn negatively affected their coaching performance. This supports the need for coaches to keep their composure and stay calm during important events (Olusoga et al., 2012). In order to manage their emotions, coaches discussed strategies they perceived to be effective such as demonstrating positive body language and attitudes around their players (Donoso-Morales et al., 2017). Furthermore, British Olympic coaches discussed the use of psychological skills as an effective strategy to cope with Olympic stressors (Olusoga et al., 2012). The importance of the coach staying calm during competition has also been discussed in an interview conducted with Pat Summitt where she discussed the importance of remaining composed if she expected her players to play with poise in a pressured situation (Wrisberg, 1990).

A second critical element of the coach's leadership style is their communication skills. In fact, communication has been identified as a central element for success during competition since all facets of the coach and athlete interaction revolve around this process (Bloom, 1996; Bloom \& Salmela, 2000; Olusoga et al., 2012). As such, coaches must have the ability to know what to say and when to say it to enhance athlete/team performance (Bloom \& Salmela, 2000). The communication style also depended on how many opportunities they had to speak with their athletes (Bloom, 1996). For example, expert gymnastic coaches were considered passive observers during performances to avoid mentally overloading their athletes with information that could interfere with their ability to attend to task-relevant cues (Côté et al., 1995; Nideffer, 1986). More specific to the type of feedback provided in the context of an individual sport, Halperin, Chapman, Martin, Abbiss, and Wulf (2016) investigated the feedback provided by boxing coaches between match rounds. The results indicated that coaches of winning bouts 
provided significantly more positive feedback than coaches of losing bouts, while coaches in losing bouts also tended to implement more controlling feedback compared to coaches in winning bouts (Halperin et al., 2016). Similarly, Smith and Cushion (2006) studied professional youth soccer coaches and found both the type of feedback and the moment it was provided were crucial for creating a positive and supportive learning environment that facilitated player performance. The most striking finding from this study was the amount of time coaches spent in silent monitoring (Smith \& Cushion, 2006). More specifically, coaches spent $40.38 \%$ of game time observing in silence. Periods of silence were punctuated with verbal cues as well as praise and encouragement. In fact, silent monitoring was an intentional strategy used by coaches which allowed them to analyze the game (Smith \& Cushion, 2006). Therefore, it is crucial for coaches to have the ability to manage their emotions in addition to having good communication skills to positively influence their athletes' performances. Coaches have mentioned that these elements take many years to refine and that it is an ongoing process (Bloom \& Salmela, 2000).

Post-competition. The last phase of the competition component occurs once the competition is over. This is an important time where coaches interact and provide feedback to their athletes (Bloom et al., 1997). Prior to talking to their athletes post-game, coaches need to take some time for themselves to gain composure and create a post-game message for their team (Bloom 1996; Bloom \& Salmela, 2000). With regards to the message delivered during the final meeting, Martens (1987) suggested that the content highly depended on the outcome of the game, but more specifically on the coaches' perceptions of the athletes' effort. Furthermore, Bloom and Salmela (2000) discussed the need to keep the message short considering that this was a time where athletes were highly emotional and likely unable to take in detailed feedback. Coaches would avoid discussing technical corrections or errors observed during the game 
(Bloom \& Salmela, 2000), keeping them for the following practice or team meeting (Bloom et al., 1997).

\section{Coach-Athlete Relationship}

High-performance coaching is highly relational and includes interactions with athletes, coaches, and support staff (Mallett \& Lara-Bercial, 2016). More specifically, the relationship between the coach and the athlete is fundamental in the coaching process considering that its quality and nature can affect the athlete's satisfaction, self-esteem, and performance accomplishments (Jowett \& Meek, 2000). Therefore, the following section will address the conceptualization of the coach-athlete relationship, as well as different factors that influence the quality of this relationship.

3+1Cs Model. A positive coach-athlete relationship can influence performance outcomes and is a crucial element for success in a high-performance sport environment (Mallett \& LaraBercial, 2016). More specifically, the coach-athlete relationship is defined as a situation where the coach and athlete's feelings, thoughts, and behaviours are interdependent (Jowett, 2007). According to Jowett and colleagues, the interdependence between these three variables forms the premise of the $3+1 \mathrm{Cs}$ (Closeness, Commitment, Complementarity, and Co-orientation) conceptualization of this relationship that has been extensively used to study the coach-athlete relationship (Jowett, 2007; Jowett \& Cockerill, 2003; Jowett \& Meek, 2000). Closeness refers to the affective component which includes mutual trust, respect, appreciation, and interpersonal liking. Commitment refers to the cognitive component and includes thoughts of attachment as well as the intention to maintain the athletic relationship in the long-term (Jowett, 2007). Complementarity reflects the behavioural component which is characterized by the cooperative interactions between the coach and athlete and includes readiness, easiness, and friendliness 
(Jowett, 2007). Finally, the additional construct of Co-orientation reflects the establishment of a common frame of reference that includes shared goals, beliefs, values, and expectations (Jowett $\&$ Cockerill, 2003). Co-orientation can be developed through open channels of communication that allows coaches and athletes to share each other's experiences, beliefs, values, thoughts, and worries (Jowett \& Cockerill, 2003). More specifically, a crucial dimension that contributes to the development of this construct is empathetic understanding (Lorimer \& Jowett, 2012). Therefore, the coach-athlete relationship is considered interdependent if members experience high levels of respect and trust, intend to remain attached and committed to the relationship, and behave in a responsive, friendly, and easygoing manner (Jowett, 2007). However, if the quality of the relationship is compromised through negative closeness (distrust), dis-orientation (incongruent goals) and non-complementarity transactions (power struggles), athletes will experience stress and could be distracted (Gould, Guinan, Greenleaf, Medbery, \& Peterson, 1999; Jowett \& Meek, 2000). In fact, considering that the manifestation of anxiety has been shown to have negative effects on performance, it becomes important to consider how the interpersonal relationship between the athlete and the coach can influence the degrees of sport anxiety in athletes (Baker, Côté, \& Hawes, 2000). As such, Baker and colleagues (2000) found that negative personal rapport behaviours such as feeling intimidated or fearful of their coach, were significant predictors of anxiety outcomes in varsity athletes. Also, athletes' anxiety levels increased in the absence of competition strategy behaviours such as having consistent routines and showing confidence in the athlete (Baker et al., 2000). Therefore, it appears that if the coach-athlete relationship is a source of stress and anxiety for the athlete, the athlete's performance can potentially suffer. 
Factors influencing the coach-athlete relationship. Considering that the coach-athlete relationship can induce anxiety in athletes, it becomes important to consider factors that contribute to the development of a positive coach-athlete relationship. As such, Mallett and LaraBercial (2016) profiled the coach-athlete-performance relationship among highly successful (or serial winning) coaches. Among their findings, coaches were described as "benevolent dictators" by their athletes, which meant they often were forced to make tough decisions with the athletes' best interests at heart (Mallett \& Lara-Bercial, 2016). More specifically, these coaches created a collaborative environment which was characterized by open communication, consensus decision making, and support for athlete initiative in problem solving. Although coaches were found to make final decisions, they sought athlete feedback in the process. This collaborative coachathlete relationship was found to contribute to successful performance outcomes (Mallett \& Lara-Bercial, 2016). Therefore, coaching at the highest levels, such as the Olympic Games, is often considered more of a partnership rather than a hierarchical power relationship (Davis \& Jowett, 2014; Hodge, Henry, \& Smith, 2014; Mallett, 2005). In turn, there are multiple factors that have been identified to influence the quality of this partnership including relationship type (gender, length, competition level) and personal characteristics of the coach and athlete (personality, efficacy beliefs, passion).

Jowett and Nezlek (2011) investigated the interdependence of the coach-athlete relationship among individual sport athletes and their coaches and found that female dyads reported higher levels of satisfaction with training and instruction compared to dyads of other gender combinations. In fact, the lowest levels of relationship interdependence and satisfaction were observed among dyads comprised of a female coach and a male athlete (Jowett \& Nezlek, 2011). Furthermore, associations between interdependence and satisfaction was stronger for 
higher-level competitors (regional, national, international) compared to lower-level competitors (club) (Jowett \& Nezlek, 2011). Finally, the interdependence and satisfaction with the coachathlete relationship was stronger for relationships of longer durations (Jowett \& Nezlek, 2011). Similarly, Jowett (2008) found that academy athletes involved in a variety of individual and team sports who had relationships with their coach extending beyond three years in duration perceived higher levels of closeness, commitment, and complementarity compared to athletes who had developed relationships with their coaches over shorter periods of time. Athletes who had longer established relationships with their coaches also reported feeling more competent, skilled, and capable (Jowett, 2008).

Additionally, it appears that there are multiple personal characteristics of both members involved in the relationship that can potentially influence the quality of the coach-athlete relationship (Jowett, Yang, \& Lorimer, 2012; Yang, Jowett, \& Chan, 2015). For example, Yang and colleagues (2015) investigated the influence of different personality factors on the relationship quality among Chinese coach-athlete dyads involved in individual and team sports. They found that factors such as conscientiousness, which refers to the tendency to show selfdiscipline, act dutifully, and aim for achievement, positively predicted one's own perceptions of the quality of the relationship whereas neuroticism, which refers to the tendency to experience negative emotions and emotional instability, negatively predicted the perceptions of coaches and athletes (Yang et al., 2015). Furthermore, Jowett and colleagues (2012) investigated the associations between personality, relationship quality, perceptions of coach empathy, and satisfaction with training to find that athletes' levels of agreeableness which refers to the tendency to cooperate, reassure, trust, and understand others positively predicted perceptions of relationship quality with their coaches (Jowett et al., 2012). It also appears that factors such as 
agreeableness, extroversion, and conscientiousness predicted levels of closeness and commitment among coaches and athletes (Jackson, Dimmock, Gucciardi, \& Grove, 2010). In fact, the importance of developing trusting relationships has been reported by highly successful and experienced university coaches of men's team sports in helping first-year athletes to transition from high school to university (Kim, Bloom, \& Bennie, 2016). As such, coaches relied on the leadership of senior athletes to create a supportive environment. Furthermore, coaches supported their athletes by being patient with their development, assisted with role acceptance on the team, helping to improve physical conditioning, monitoring academic progress, and advocating for the use of resources available such as tutoring or support programmes (Kim et al., 2016). In turn, these high levels of support allowed athletes to successfully transition as well as learn important life lessons and skills (Kim et al., 2016).

Furthermore, it has been suggested that other personal characteristics such as different types of efficacy beliefs appear to influence the perceptions of the relationship quality (Jackson, Grove, \& Beauchamp, 2010). For example, Jackson and colleagues (2010) found that higher degrees of confidence of the other member's capabilities predicted levels of closeness and commitment among junior tennis athletes and their coaches. Also, passion is another characteristic that appears to influence the quality of the relationship. More specifically, Lafrenière, Jowett, Vallerand, Donahue, and Lorimer (2008) investigated the role of passion in the coach-athlete relationship and found that harmonious passion, which refers to the desire to freely and autonomously engage in an activity, predicted high-quality relationships. As such, athletes were highly interdependent with their coaches in terms of closeness, commitment, and complementarity (Lafrenière et al., 2008). In a similar manner, Lafrenière, Jowett, Vallerand, and Carbonneau (2011) found that coaches who had harmonious passion were more likely to 
display autonomy supportive coaching behaviours involving taking athletes' perspectives into account, providing their athletes with rationales, and encouraging self-initiative (Lafrenière et al., 2011). Therefore, athletes who feel cared for, understood, and respected by their coach are more likely to invest time and energy to develop positive relationships (Jowett \& Shanmugam, 2016). This was highlighted in a study by Duchesne, Bloom, and Sabiston (2011) who explored the knowledge and experiences of women's intercollegiate soccer coaches who worked with many international athletes. Among their conclusions, the coaches were concerned with the holistic growth of their athletes which included developing them athletically, academically, and personally, while helping them learn to live in a new country (Duchesne et al., 2011). To achieve this, coaches employed strategies to better suit the needs of their athletes such as including team building activities and having an open-door policy. Coaches also made an effort to learn about their athletes' cultural backgrounds and practices (Duchesne et al., 2011). Therefore, these findings suggest that coaches were involved in athletes' lives beyond sport and put strategies in place to ensure their integration to the team. In fact, this supports the idea that developing a good quality coach-athlete relationship is likely to determine the presence of effective coaching behaviours. As such, Olympiou, Jowett, and Duda (2008) found that athletes who had high trusting, respectful, co-operative, and committed relationships with their coaches perceived them to be more task-oriented and focused on athlete learning and skill development as opposed to outperforming competitors. Therefore, it appears that the different factors influencing the quality of the coach-athlete relationship also contribute to the manifestation of coaching effectiveness.

Finally, the way in which the coach-athlete relationship is developed may differ depending on the context. Specifically, differences exist in this relationship between athletes in team and individual sports (e.g., Baker, Yardley, \& Côté, 2003; Jowett, Paull, \& Pensgaard, 
2005). More specifically, athletes in individual sports have experienced higher levels of closeness, commitment, and complementarity to their coach than athletes in team sports (Rhind, Jowett, \& Yang, 2012). This may be due to increased opportunities that individual sport coaches have to interact with their athletes on a one-on-one basis compared to coaches of team sport athletes (Rhind et al., 2012; Salminen \& Liukkonen, 1996). Related to this, individual sport coaches might focus more on developing a relationship with each individual athlete compared to coaches of team sports who might be more focused on developing team-related outcomes, such as cohesion (Bloom et al., 2014; Jowett et al., 2005). Therefore, the quality of the relationship may differ depending on the context which may influence coach and athlete satisfaction with the relationship (Davis, Jowett, \& Lafrenière, 2013; Jowett \& Ntoumanis, 2004; Lorimer, 2009), performance, training, and coach treatment (Jowett, 2009; Jowett, Shanmugam \& Caccoulis, 2012).

\section{Conclusion}

In conclusion, effective coaches consistently apply a combination of professional, interpersonal, and intrapersonal knowledge to successfully develop positive outcomes in their athletes in specific contexts (Côté \& Gilbert, 2009; Gilbert \& Côté, 2013). In high-performance sport, it also appears that developing quality coach-athlete relationships are likely to result in the demonstration of effective coaching behaviours, which in turn positively influence performance outcomes (Jowett \& Shanmugam, 2016; Mallett \& Lara-Bercial, 2016). As such, coaches play a crucial role during competition since their behaviours can influence their athletes' performance (Allain et al., 2018; Bloom et al., 1997; Bloom et al., 2014; Gould et al., 2002; Olusoga et al., 2012). In fact, coaches are involved during all phases of competition by assisting athletes with the preparation as well as communicating effectively with athletes during competition (Bloom, 
1996; Bloom \& Salmela, 2000; Côté et al., 1995; Haleprin et al., 2016; Olusoga et al., 2012; Smith \& Cushion, 2006; Vargas \& Short, 2011; Vargas-Tonsing \& Guan, 2007). In order to be effective during crucial moments, coaches develop well-structured routines for both themselves and their athletes leading up to competition as well as during the competition (Allain et al., 2018; Bloom, 1996; Bloom \& Salmela, 2000). Coaches use different strategies during the competition that will result in optimal performance from their athletes which mostly includes analyzing contextual factors as well as the physical and emotional states of their athletes (Allain et al., 2018; Duke \& Corlett, 1992; Gilbert et al., 1999). Therefore, coaches play an important role in assisting their athletes perform to their potential during competition. 


\section{Chapter 3}

\section{Methods}

In qualitative research the researcher relies on text data, analyzes those data in their textual form, aims to understand the meaning of human action, and asks open questions about phenomena as they occur in context (Schwandt, 2001). The current chapter will include a description of the qualitative methods used to address the research questions guiding this study.

\section{Philosophical Assumptions}

Philosophical assumptions that underlie qualitative research help to guide the research questions that are formed and how information is sought to answer these questions (Huff, 2009; Poucher, Tamminen, Caron, \& Sweet, in press). In fact, all forms of scientific inquiry are rooted in a set of assumptions about the fundamental nature of human beings (Daly, 2007). More specifically, the researcher's beliefs and assumptions shape the way in which the research process is conducted (Daly, 2007). These beliefs and assumptions shape the premises of ontology and epistemology (Daly, 2007). As such, ontology refers to the set of beliefs about the nature of reality and the nature of being (Daly, 2007). There are different ontological positions including realism and relativism (Sparkes \& Smith, 2014). Realism assumes there is a single truth that can be accessed through the rigorous application of methodological techniques and is typically used in quantitative research (Sparkes \& Smith, 2014). On the other hand, relativism argues that there are multiple socially constructed realities that vary across time and context (Sparkes \& Smith, 2014). Typically, qualitative research embraces the idea of multiple realities, thus supporting a relativist ontology (Sparkes \& Smith, 2014). Additionally, this ontological position is appropriate for this study as the knowledge constructed highly depends on the perspective of the individual (Sparkes \& Smith, 2014). 
Epistemology, which refers to the nature of knowledge, is another important consideration in the context of qualitative research (Schwandt, 2001). Quantitative researchers tend to hold a positivist approach where it is believed that a single truth can be studied objectively. In contrast, qualitative researchers adopt a constructionist approach (Creswell, 2013; Sparkes \& Smith, 2014). More specifically, in line with a relativist ontology, the present study used a constructionist epistemology in which knowledge is a product of a socially constructed understanding of the external world (Braun \& Clarke, 2013; Smith \& McGannon, 2018). From this perspective, the researcher is involved in the construction of knowledge. As such, it is important to acknowledge researchers' beliefs and assumptions shaped through the interpretation of their experiences (Braun \& Clarke, 2013). Therefore, it is important for researchers to be aware of how their expectations could potentially affect their interpretations and be cautious not to impose them on the participants (Braun \& Clarke, 2013).

\section{Methodology}

Methodology refers to the framework in which the research is conducted and includes theories and practices that guide the process (Braun \& Clarke, 2013). Methodology drives the methods used to develop and create knowledge. As such, various classifications of qualitative approaches have surfaced over the years, which include narrative research, phenomenology, grounded theory, ethnography, and case study (Creswell, 2013). More specifically, case study research involves studying a case with a real-life, contemporary context or setting (Yin, 2009). A case study is characterized by different elements including the identification of a specific case comprised of an individual, a small group, an organization, or a partnership to achieve an indepth understanding of the case (Yin, 2009). In the current investigation, a collective case study approach was used which involved selecting multiple cases to address the research questions by 
providing multiple perspectives on the topic (Creswell, 2013). The individual cases of multiple participants having experienced the same phenomenon are studied together to gain an in-depth understanding of the topic (Sparkes \& Smith, 2014). As such, this study attempted to identify common themes within multiple elite individual sport athletes' experiences with their coaches in competition.

\section{Participants}

Qualitative researchers often have to make informed and strategic choices about which participants may have the experiential knowledge to explore the research questions of interest (Sparkes \& Smith, 2014). Furthermore, sampling in qualitative research is often described as purposeful in which participants are invited to participate in the study because of their experiences and knowledge related to a certain topic (Sparkes \& Smith, 2014). For the current study, experiences of elite divers (those competing at the international level) with their coaches during competition were of interest. Among the different purposeful sampling techniques that exist, this study used a criterion-based sampling (Sparkes \& Smith, 2014). In this approach, participants are selected based on a set of predetermined criteria because they have a particular feature, attribute or characteristic, or have specific experiences (Patton, 1990). The participants in the current study were selected based on their experiences defined by the following criteria: (a) active or retired (within the past three years) divers, (b) competed at the international level for a minimum of 5 years, (c) participated in at least one World Championship or Olympic Games, (d) male or female and over the age of 18 . Of the sample of individuals who fit the selection criteria, six agreed to participate in the study. Athletes in this sample had been diving for a range of 15 to 24 years, and were members of the Canadian national diving team for 7 to 15 years. This sample included three females and three males between 20 and 31 years of age. Three 
specialized in platform events while the other half competed in springboard events. All athletes competed in both individual and synchronized events at the international level. This sample experienced tremendous success on the world scene as evidenced by winning a total of 42 medals at various international competitions (i.e.., Olympic Games, World Championships, Commonwealth Games, and PanAmerican Games). All athletes competed at a World Championship, with four of the six athletes making at least one appearance at an Olympic Games. All athletes were aiming for the Tokyo 2020 Olympics that was subsequently postponed due to the pandemic. Throughout their careers, athletes had between two to five coaches, while being with their current coach between four and eleven years. Athletes' current coaches included three males and one female.

Procedures. Prior to recruiting participants, approval was obtained by the McGill University Research Ethics Board. Following approval, the primary researcher engaged in two pilot interviews prior to beginning data collection to become more familiar with the interview process and to gain interviewing experience. This enabled the research team to refine and adjust the interview guide (see Appendix C). The pilot interview recording was then analyzed by the research supervisor who has had extensive experience in qualitative interviewing. Based on the feedback provided by the research supervisor, the primary researcher adjusted questions in the interview guide and improved interviewing techniques. Then, participants were recruited by email through personal contacts of the researcher with a brief description of the study (see Appendix A). Among the individuals contacted, those interested in participating in the study were provided with a detailed description of the data collection procedures. An interview was then scheduled based on the participants' preferred time and location to conduct the interview. Prior to the start of the interview, a consent form (see Appendix B) was provided to the 
participants and was collected in person. Interviews were audio recorded and transcribed verbatim. The primary researcher took notes during and after the interview to supplement the audio recording and capture any observed details (Creswell, 2013). Different identification codes were used in the transcripts to maintain the confidentiality of the participants by altering their names and personal information.

\section{Data Collection}

There are multiple methods of data collection used in qualitative research such as observations, interviews, documents, and audio or visual materials (Creswell, 2013). Interviews are the most common method of qualitative data collection in the sport and exercise sciences (Smith \& Sparkes, 2016). However, the use of interviews in the sociology of sport, sport and exercise psychology, and sport coaching is often taken for granted since justifications for their use and appropriateness are relatively rare (Smith \& Sparkes, 2016). Interviews are a particularly useful way for people to describe their experiences in a rich and detailed manner while also providing their perspectives and interpretations of these experiences (Smith \& Sparkes, 2016). Therefore, interviews are valuable sources of rich and new knowledge about experiences and meaning through conversation (Smith \& Sparkes, 2016). Furthermore, interviews can provide insight into temporal dimensions of one's life including past events, the present, and imagined futures (Smith \& Sparkes, 2016). Therefore, participants are encouraged and invited to tell stories, accounts, reports, and descriptions about their perspectives, insights, experiences, feelings, emotions, and behaviours in relation to the research questions (Smith \& Sparkes, 2016). This method of data collection provides the researcher with the opportunity to get to know the participant through conversation (Smith \& Sparkes, 2016). In addition to interviews, documents 
will also be used as a means of data collection to help understand the experiences of elite individual sport athletes (Creswell, 2013).

The interviewer biography. Due to the nature of the study, the researcher was highly involved in the data collection process which involves interacting with participants during the interviews. Consequently, the role of the researcher in the process was not neutral (Sparkes \& Smith, 2014). The researcher had to be aware of her expectations and biases to prevent from imposing them on the participants. Therefore, it was important to consider the experiences of the researcher as they contributed and shaped the research process.

As such, the athletic experiences of the lead author consisted of 14 years of competing in the diving springboard events at the senior national level. The author is a member of the "Elite" Team Quebec who received the "Trophée Philippe Comptois" (following the 2017-2018 season) awarded annually by Plongeon Québec to an athlete who demonstrated perseverance and tenacity in the face of adversity. The author was the recipient of the 2017-2018 student/athlete award at the cégep and university level awarded by Plongeon Québec. The author received the Best Female Senior Athlete of the 2018-2019 season awarded by Plongeon Québec.

In addition to the personal athletic experiences, the researcher's academic background has provided many opportunities to work in different sport settings. As such, the author completed an undergraduate degree in kinesiology where she took a research practicum course that allowed her to learn about coaching effectiveness and qualitative research methodologies. Furthermore, the author is a NCCP certified coach in diving and has had experience coaching youth at the regional level over a period of five years. The author is currently the strength and conditioning coach for a group of junior divers on the "Relève" Team Quebec and has had experience working as a personal trainer in a local gym over the course of two years. 
Interviews. There are different categories of qualitative interviewing that are used in different contexts (Rubin \& Rubin, 2012). As such, interviews vary based on the structure, the role of the researcher, the number of participants involved, whether they are being conducted face-to-face or at a distance, the extent to which they are planned, and how well acquainted the interviewer and interviewee are with one another (Rubin \& Rubin, 2012; Smith \& Sparkes, 2016). More specifically, the individual semi-structured interview is an extended conversation between the researcher and interviewee with a focus on a specific topic. It typically involves a limited number of open-ended questions that are prepared in advance to guide the conversation (Rubin \& Rubin, 2012; Smith \& Sparkes, 2016). The interviewee is encouraged to provide in depth answers with vivid detail which can be achieved by using probes and follow-up questions by the researcher. Although the individual semi-structured interview provides the interviewer with a certain level of control throughout the discussion, there is also flexibility to ask unplanned questions as conversations unfold. Consequently, the structure of this interview promotes the ability to generate knowledge and additional insights in the process. Therefore, individual semistructured interviews were an appropriate tool of data collection for this study as they allowed the researcher to focus on items that specifically related to the research questions while also providing space for the participant to direct the conversation and share what was personally meaningful to them (Rubin \& Rubin, 2012; Smith \& Sparkes, 2016).

Interview guide. The interviewer began with a set of opening questions designed to establish rapport with the participant and provide a brief description of their athletic career (see Appendix C). The interviewer then guided the discussion to the key questions (Smith \& Sparkes, 2016), which focused initially on the athletes' experiences with coaching behaviours in the context of competition in terms of what they do, what they say, for how long, etc. Then, the 
focus was on the athletes' perceptions of the quality of their relationship with their coaches and how this was reflected in the context of competition. Then, athletes were asked about their desired coaching behaviours and interactions in this context. Considering that this is an individual semi-structured interview, probes and follow-up questions were used to get in-depth responses from the participants which provided additional information (Smith \& Sparkes, 2016). Different types of probes were used including detail-oriented probes to gain a better understanding, elaboration probes to encourage the participant to say more about a particular point, and clarification probes to seek clarification (Smith \& Sparkes, 2016). The interview then followed with summary questions and concluding questions (Smith \& Sparkes, 2016).

Documents. In case study research, data collection often involves drawing on multiple sources of information (Creswell, 2013). As such, documents that are publicly available or in written form such as newspapers, magazines, public health information leaflets, textbooks, blogs, websites, minutes of meetings, or official reports can provide additional information on the case being studied (Braun \& Clarke, 2013; Creswell, 2013). Documents were used in the current study, and included athlete biographies, previous athletic records, as well as results from previous competitions. These documents provided the researcher with a more in-depth understanding of the athlete's career as well some defining moments. This information also allowed the researcher to comprehend to a greater extent the responses of the athletes which led to a greater understanding of their experiences with their coaches in the context of competition as well as their past relationships with coaches.

\section{Data Analysis}

Qualitative data may be analyzed in a variety of ways depending on the methodology used to gather data (Sparkes \& Smith, 2014). As such, qualitative analysis is an interpretive 
process that assigns meaning to the data collected. It involves multiple steps including transcription, data management, immersion in collected data, a concern with the content of the collected data, an examination of any possible interrelationships, and a reflexive awareness of the processes of writing and representation (Sparkes \& Smith, 2014). In line with the philosophical assumptions and methodology used in this study, a thematic analysis was used to analyze the data that was collected (Braun \& Clarke, 2013). More specifically, a thematic analysis is a method that minimally organizes and describes the data collected in rich detail by identifying, analyzing, interpreting, and reporting patterns (Braun \& Clarke, 2013). This type of analysis does not try to quantify themes or build thematic structures in a hierarchical manner as seen in other types of analyses (Sparkes \& Smith, 2014). Furthermore, writing is openly part of the analysis (Sparkes \& Smith, 2014). This type of analysis is relatively straightforward and flexible by highlighting similarities and differences across the data set and summarizing key features. This type of analysis allows for social as well as psychological interpretations of the data (Sparkes \& Smith, 2014). Braun and Clarke (2013) have delineated six phases involved in a thematic analysis.

First, immersion involves becoming familiar with the data. This was achieved by listening to the recorded interview or reading the transcript several times. The second phase involves the generation of initial codes where the researcher coded across the entire data set in a systematic way and produced a list of the different codes that have been identified (Braun \& Clarke, 2013). Once the data was initially coded, data relevant to each code was gathered and collated. The third phase refers to searching for and identifying themes which involves sorting the different codes into possible candidate themes (Braun \& Clarke, 2013). As such, the researcher considered how different codes combined to form an overarching theme which 
referred to a common thread and meaningful essence that ran through the data. A thematic map (e.g., visual representation, table, drawing) was used to sort the different codes into themes. The fourth phase involves reviewing themes to ensure that they align with the coded extracts (Braun \& Clarke, 2013). As such, the researcher read all the collated extracts for each theme and determined if a coherent pattern appeared. Adjustments to the themes or under which themes the data extracts fit occurred. It is possible to rework a theme, create a new one, or fit the extracts elsewhere in the case where they do not fit in an already-existing theme. Once the candidate themes adequately captured the contours of the coded data and a thematic map had been developed, the researcher reviewed the entire data set to ensure that the themes fit. Furthermore, any additional data that was missed in earlier coding stages was coded within themes. Then, the researcher made sure that the data within themes was coherent in a meaningful way and that clear distinctions between themes could be identified. This was achieved by referring to the thematic map. By the end of this phase, the researcher had a good idea of the themes and the relations between them. The fifth phase involves defining and naming themes to refine and define the what each theme consisted of and determining what aspect of the data each theme captured (Braun \& Clarke, 2013). The researcher had to also consider how each individual theme fit into a broader perspective in relation to the research questions. It was also during this phase that sub-themes were identified which provided structure to complex themes. The sixth phase consists of writing the report which provides another opportunity to refine the analysis (Braun \& Clarke, 2013). The report was comprised of data extracts to demonstrate the prevalence of the theme while providing a clear interpretation of the data (Sparkes \& Smith, 2014). 


\section{Trustworthiness}

The standard criteria used to judge the quality of quantitative research is not appropriate for qualitative research considering the differences in ontological and epistemological assumptions, goals, and methods (McGannon \& Schweinbenz, 2011). More specifically, Lincoln and Guba (1985) initially proposed a set of criteria to ensure rigor of qualitative research. However, recent advances in the field have since critiqued the value and applicability of their research (Smith, Sparkes, \& Caddick, 2014). For example, Smith and McGannon (2018) critically reviewed widely used ways of demonstrating rigor in qualitative research such as member checking, inter-rater reliability, and using a universal set of criteria to judge qualitative research. The use of such techniques was problematic considering that the underlying assumptions associated with these techniques were incoherent with the philosophical assumptions of qualitative research. Consequently, authors proposed constructive possibilities for conducting quality qualitative research that aligned with the philosophical assumptions guiding this type of research such as member reflections, critical friend, and flexible criteria for judging rigor (Smith \& McGannon, 2018). Therefore, based on the relativist ontological perspective adopted in this study, the researcher was not under the mandate to commit to a set of universal criteria to ensure rigor, but rather the criteria selected could be changed based on the context and purpose of the specific research being judged (Smith \& McGannon, 2018). Therefore, the criteria selected for this study to ensure rigor and quality that aligned with the researcher's philosophical assumptions will be discussed in the following section.

Critical friend. Achieving rigor in qualitative research can be done via the use of 'critical friends' which is a process that involves engaging in a critical dialogue (Smith \& McGannon, 2018). This is also a strategy used to enhance the reflexive self-awareness of the 
researcher (Sparkes \& Smith, 2014). As such, researchers give voice to their interpretations in relation to other people who listen and provide critical feedback. Therefore, the role of the 'critical friend' is to encourage reflection by challenging the researcher's interpretations to explore alternative explanations (Smith \& McGannon, 2018). In the context of this study, a doctoral student in the sport psychology laboratory served this role. The role of this individual involved engaging in discussions with the lead researcher to bring her to reflect on her findings. The critical friend questioned and challenged the researcher's views in the analysis and interpretation of the results.

Substantive width and contribution. In order to reach substantive contribution and width, the participants in the study were purposively recruited to ensure that the sample of participants was elite (Smith et al., 2014). This provided insight on what elite individual sport athletes expected and wanted from a coach in the context of competition. Additionally, quotations were provided in the results section for the reader to interpret the findings themselves (Smith et al., 2014). This supports the comprehensiveness and quality of the evidence provided as well as the proposed interpretation or analysis. 


\section{Chapter 4}

\section{Results}

This chapter presents the results of individual interviews with six elite divers. The initial interviews ranged from 29 to 92 minutes, with one additional follow-up interview. In total, the interviews were 395 minutes in duration. Further, the interviews were transcribed verbatim to produce 79 single-spaced pages of text. The thematic analysis allowed us to organize data into 41 codes, eight themes, and finally three overarching themes, that were called: background and characteristics, coach-athlete relationship, and coaching strategies and behaviours (see Table 1). The following chapter will provide descriptions along with the participants' own words to illustrate each of the three overarching themes in detail. Moreover, pseudonyms (e.g., Taylor) will be used throughout the results section to protect the participants' confidentiality.

\section{Background and Characteristics}

This overarching theme encapsulates the experiences and characteristics of athletes and coaches that contributed to their behaviours and success. This section is split into the themes of athlete experiences and characteristics and coach experiences and characteristics.

Athlete experiences and characteristics. This section includes the experiences and attributes of the athlete. Related to their athletic careers and evolution, all athletes became members of the Canadian national diving team and experienced tremendous success on the world scene. These athletes have been awarded a total of 42 medals at various international competitions, which they partly attributed to various personal characteristics including passion for the sport, having a strong work ethic, being autonomous, perseverant, and having a strong desire to improve: 
I asked myself 'What do I need to change to go to the Olympics and to be the athlete that I want to be and be on top all the time?' So then, I changed everything. I changed the way I ate, trained, my mentality, and everything. I started making some big changes and it started working. I think that's when my career really started as a high-performance athlete (Charlotte).

There are a lot of people who were super talented but never really had a breakthrough because they didn't know how to work or how to train. I think I had that in a sense. I was able to put in everything that I had when I was a kid and tried to make it work by myself (Taylor).

Furthermore, coaches played a role in developing and reinforcing athlete characteristics such as having a strong work ethic and desire to succeed: "I think my coach really instilled a work ethic that I still have. And I think that's really what helped me get better during my career" (Mason). These athlete characteristics contributed to shaping their expectations with regards to competition:

You could always do something better, even if they tell you it's good. Because if you do that in competition and you get nine, you're like 'I told you, I could have done better. I didn't get a ten. The goal is to get tens.' You taught me how to be hard on myself. That's what you get (Kate).

In conclusion, these highly decorated athletes demonstrated similar attributes that enabled them to reach the highest levels in their sport. Such characteristics were developed and enhanced by their coaches throughout their careers. 
Coach experiences and characteristics. This theme relates to the experiences and attributes of the coach. This includes elements related to building athlete character and coach demands and expectations. Coaches held their athletes to high standards:

There was a lot of structure in my coach's training and you couldn't skip anything in the warm-up. You couldn't skip any dive or you couldn't even try to do an extra of each, a repetition if you wanted to. It was just do what it says on the list. So I think their plan worked. I mean, I think with my results in the past 10 years, I showed that that was good for me (Taylor).

Many of the coaches' behaviours in competition were shaped by previous experiences coaching at this level:

My coach knew how to manage the nerves at the Olympics. That's why I don't think I've ever had any big problems like that with my coach. He has coached other top divers so he knows how to manage that situation (Kate).

Although coaching experience contributed to shaping the coaches' style and behaviours in competition, the personal characteristics of a coach also played a large part in athlete success. Personal characteristics including passion for the sport, as well as the coaches' emotional state were important: "My coach is pretty good at keeping her cool and being there for the athletes. That's what her job is but you don't see her get nervous very often. She's got a pretty good poker face" (Laura).

I think for coaches it's hard not to be emotionally involved in performances of their athletes because they're so dedicated to what they do and they're working with us yearround. It's as if it was their performance (Mason). 
Based on how my performance is going, the corrections won't change but I'll notice he gets excited. You know, like he knows it's going well and if it's going well, he'll crack jokes here and there. When it's not going well, he will kind of be gloomy. So I know what he's thinking. But I try not to be affected by it (Adrian).

In conclusion, a combination of athletes' and coaches' characteristics and experiences provided the foundation for them to operate and perform successfully at this level. These elements contributed to shaping both athlete and coach expectations for competition which in turn, influenced their behaviours in this context. Athletes' interpretations and reactions to their coaches' behaviours in competition are shaped in part by the relationship they have with their coach.

\section{Coach-Athlete Relationship}

The following overarching theme represents the positive and negative factors of the coach-athlete relationship influencing all facets of their partnership. It is split into two themes: coach-athlete closeness and coach-athlete challenges.

Coach-athlete closeness. This section includes aspects of the relationship between the coach and athlete reflecting their appreciation of the partnership and how it positively influenced their interactions. Athletes described forming a unique bond with their coaches and referred to them as friends, family, or parent: "I think my coach is kind of a father. He's always gonna put his kids forward, up front. And that's what he does with us. He's definitely a father figure for most of us" (Taylor). Some of the key features defining this partnership included the coaches caring for the athletes, coaches' continuous support, and the development of trust:

I think having a good relationship with someone builds your trust and I think that with diving especially, that's a big factor. We're up there on the tower alone, we're going to 
chuck ourselves off, and sometimes we're really scared. We're not thinking rationally and our bodies are like 'This is not natural. Why are you doing this?' But we've worked a lot with the coach. The coach knows you, your body, how you act. I think having that relationship and having that trust in that coach or person, it helps. It's that kind of trust of believing that they're going to do the right thing for you and that they're there for you (Laura).

My coach wants us to perform because he likes us. He sees us working every single day. He is with us. He's been my coach for so many years that he wants me to perform because he believes I deserve it, not because he thinks he's the best coach (Taylor). Something that I need from my coach is to have him always there regardless of the outcome. Always supportive, always there for me regardless of the event. I know that sometimes it can be super good and sometimes I can be horrible. Just having him there through everything is something that I need. I need that attention. I need to know that he's there, even during my practices (Kate).

Additionally, athletes also discussed the value of having their coaches believe in them: "My coach was like, 'There's still so much potential in you.' Just to have someone tell you that, that's where you trust your coach. The fact that people believe in you, that they're confident that you could be better" (Kate). The development of trust allowed athletes to have confidence in what their coaches were telling them:

Coaches are one of the pillars. They are people you can rely on. They know you. I trust my coaches $100 \%$. They have my back. They know me. When they tell me something, well I listen to them. When they tell me I'm off track, usually they will tell me what I need to do (Charlotte). 
Additionally, the coaches developed closer relationships as they spent more time with their athletes. This allowed for a better understanding of athletes' perspectives and reactions in specific situations:

My coach knows when you need to be motivated and when you don't. He knows when you're feeling down. He knows right away when we're sore, when we're tired. That's something that we appreciate from a coach. It's nice to have someone that could pick up on those things and who really understands each athlete, what each athlete needs at what moment. We're five divers with him I think right now and we're all completely different. I think he takes the time to understand us all as individuals (Kate).

I feel like a relationship with a coach and athlete is like a couple. You have to understand each other. You have to respect some limits and you have to understand how the other person is feeling or acting. It takes months and years of learning who that person is and how he's going to react to certain situations. With my coach, our first year was kind of a mess because we were trying a lot of things. But when we found out what worked best for me, that's when I managed to perform better (Taylor).

Considering that coaches and athletes spent a lot of time together travelling and during training and competitions, having a positive environment was unsurprisingly very important for athletes. In fact, coaches appeared to play a role in fostering this environment:

When we have a good coach-athlete relationship, we can talk, we can laugh and have fun and we can be serious when we need to be serious. I think that makes a good environment for the coach and that's what I expect from them (Charlotte).

I always loved diving obviously but my coach made me enjoy diving more. Even if it was a job, to really enjoy what I was doing. Obviously, there are hard times, ups and downs, 
but to really enjoy what I was doing and to find the fun in the practices, coming to the pool, and just laughing (Kate).

In conclusion, athletes highlighted key features of the relationship with their coaches that were important to them including trust, support, and developing a mutual and caring understanding. In turn, investing energy in the development of the relationship appears to be important for coaches and athletes to function effectively together.

Coach-athlete challenges. This theme relates to coach behaviours that distract athletes from focusing on the task at hand. It appears as though a balance must be found in terms of closeness between the athletes and the coaches:

Having a personal relationship with your coach could lead to more conflict. I think there's a balance between keeping a certain distance and knowing the person on a personal level to try to understand how they function and try to adapt yourself to how they work (Mason).

Furthermore, some of the challenges related to the partnership stemmed from a lack of understanding between the coach and athlete: "Sometimes, because of that lack of understanding, they won't be working as well with us and I guess they'll get frustrated with us a bit more" (Mason). In fact, this mutual understanding appeared to depend in part on communication: When you keep repeating the same thing over and over and you see that it's not working, you need to find a different way or something else to say so that the athlete understands it. It can be the same correction just said in a different way. Then, the athlete will be like 'Ah that's what you mean' (Kate). Additionally, the athletes were influenced by their coaches" emotions: "The mood of my coach affects me. I don't know one athlete that doesn't get affected by the coach's mood" (Charlotte). 
This occurred during a competition: "The coaches need to avoid getting emotional in the middle of a competition. The athlete knows they missed and doesn't need to be reminded. Bring that up maybe after competition" (Mason). Athletes also interpreted the emotions in different ways:

If the coach is too emotional about the competition, then sometimes it could affect you in a negative way. If they're not emotional enough, sometimes it could make you feel like they're not involved in how you're performing (Mason).

More specifically, athletes struggled when they felt as though their coaches were frustrated, disappointed, or were giving up on them:

It happens that we miss a dive. Then, when you feel like your coach is giving up because you missed a dive, that doesn't help me. We've had that happen before and we talk about it after. We try to make a change because you're going to miss some dives sometimes (Charlotte).

When a coach is disappointed, that's something that I think is very hard to deal with and it doesn't happen often with my coach, but it still happens. We're very human and we still make mistakes and you deal with it. You try to be confident. You try to look for the positive side of whatever outcome it is (Kate).

Let's say a coach has a bad day or something. Sometimes, they come in and they're just pissed off in the morning. Then they start coaching you and they're pissed. They're giving you corrections with an angry tone of voice and you kind of get the feeling that it's because they're angry at you. That could affect you (Mason).

Athletes were also influenced by their coaches' energy and attitudes:

Usually, my coach is pretty positive during competition. Even if I miss a dive, my coach kind of moves on. But sometimes, my coach doesn't move on and that can be really 
critical in how I compete. No matter how hard you try to avoid getting influenced by how a coach is acting, it's going to affect you (Laura).

The challenges encountered affected athletes in different ways including becoming a barrier to communication: "It's hard to communicate with my coach when he's angry so we kind of shut down a little bit” (Laura).

Taken together, interactions and communications between the coach and athlete suffered in instances where there was a lack of mutual understanding and the coaches' frustrations and disappointment affected the athlete. In addition to this understanding, other elements facilitating coach and athlete interactions included coach caring, support, and trust. Consequently, these interactions have the potential to influence the coaching strategies used, particularly in the context of competition.

\section{Coaching Strategies and Behaviours}

This overarching theme relates to the strategies and behaviours used by coaches that influence how their athletes cope with and perform during competition. The themes making up this section include coach-athlete goals, communication, coach influence on athlete readiness, and game-day patterns.

Coach-athlete goals. Relating to the creation and establishment of goals, coaches established a yearly plan with their athletes at the beginning of the season that usually prioritized certain competitions:

We have a lot of different competitions during the season. Some of them are way more important than others. Some of them are good for practicing competition. We'll usually have to talk about it. We usually know which ones are more important like Olympic trials or Nationals to qualify for the World Championships (Mason). 
Every beginning of the season, my coach will be like 'This is what your year looks like.' We'll manage if something in between happens, but he'll always show us our blocks. It's always blocks of two to three months. There's always a goal at the end of that. We have three World Series in the month of March where one is to perform and two are going into training. Because after those two World Series, it's the World Cup. You want a peak at the World Cup (Kate).

Specifically, in competition, athletes were better able to shape performance expectations when their coaches reminded them of the goals and priorities:

My coach says 'I really want to see these changes we've been working on. If you miss some dives, it won't be that important.' We want to do as good as we can in the whole year, but we can't expect to peak the whole year. That gives me a good perspective (Mason).

If you're just training, then you don't know what's okay and what's not okay. Competition is where you see everything. As long as you're competing, that's when you're really going to see where the work has been done and what needs to be worked on (Kate).

In fact, being on the same page was essential for performance and included the mood of coaches and athletes, working towards the same goal while always striving to improve, and including athletes' input in the decision-making process:

We're open enough in our communication that we can say 'We have the same goal here. You're coaching me and I'm working with you because we both want to try to get better.' Ultimately, it's for the athlete but the goals are in line. It's to improve. If you come down on that same page, then you can talk and say 'This is what I have difficulty with.' And then, you try to improve (Mason). 
Furthermore, to be on the same page, coaches had to understand how athletes responded to different phases of training and competition. Levels of understanding also had implications in terms of how athletes progressed technically. In turn, this enabled coaches to individualize athlete goals:

We all have blocks in our seasons. We have the goal at the end of a block. Then, how we react to when it's supposed to be high intensity, low intensity, or competitions that we're supposed to perform at. Some we're just supposed to go through as if we're just training. I think that's how my coach knows how we react to things and that's how he learns that each individual is very different (Kate).

Overall, goal setting was essential to set the tone for the season and the expectations for different competitions. In order to achieve these goals and perform optimally, coaches and athletes relied on effective forms of communication to be on the same page throughout the process.

Communication. This theme includes aspects related to what and how coaches talk to their athletes in competition. Communication is a critical element with regards to the effectiveness of coach feedback and instruction in competition for optimal athlete functioning: "If my coach and I don't communicate well enough, the practices and competition are going to be affected because he doesn't know what's going on in my head" (Taylor). At the beginning of competition, coaches gave feedback and instructions to their athletes about their perception of athlete readiness, their mental or physical state, and elements to focus on:

I think the main job for the coaches is to get us focusing on the right things for the competition. And that in the competition, we're at the right place mentally and physically to do the dive at that moment (Mason). 
Prior to every dive in competition, coaches generally provided instructions to their athletes that included technical elements:

My coaches tell me basic corrections for what I've been working on. For example, if I've been lacking jump and if I've been rolling over on my entries, they'll be like 'Make sure you have power and you're jumping and you aim forward when you come out. When you come out to go for your entry and then pike save really fast' (Laura).

Instructions helped athletes when provided in the form of key words related to elements that enabled them to execute the dive well: "My coach will give me things that are more general to the dive that he knows that if I focus on these things, then I have a better chance of succeeding, of doing a good dive, really nailing it" (Mason). Key words also appeared to be most effective when framed positively: "You're really thinking about the positive and what to do instead of what not to do" (Laura). In fact, key words directed athletes' attention to the task and prevented them from overthinking: "I need to have those words in my head before I'm at the end of the board and doing my dive because then you start thinking too much if you don't listen to your coach" (Kate).

Technical instruction and feedback were also valuable for athletes with regards to management of emotions between rounds in competition:

Sometimes, going to see your coach actually helps a lot because you have that feeling like 'Why did I miss it. I should know how to do this.' You feel like crap and then, you go see the coach and they're like 'Oh it's okay you made that mistake. It was just a technical error, it's fine.' Having that perspective sometimes helps you get out of it emotionally and then regroup for the next dive. And be more efficient for the next dive 
instead of having that added load on your shoulders now mixing your thoughts for the next dive. You can't be as focused (Mason).

Although mostly technical, coaches also provided key words that included other elements such as encouragement: "My coach is gonna tell me keywords to make sure that I understand what I have to do and he's always going to tell me not to hold back and be proud of what I do in every single dive" (Taylor). In general, the effectiveness of communication relied on the contribution of both the coach and athlete. Athletes felt it was important for them to feel comfortable sharing their concerns: "It's important to have that communication where you can tell your coach if something is not working. Having good communication with my coach is really important right now" (Adrian).

Taken together, effective communication between the coach and athlete helped athletes in the context of competition. Coach feedback and instruction that included different types of information helped athletes remain focused. This demonstrates the influence coaches may have on athlete regulation in this specific context.

Coach influence on athlete readiness. This theme relates to behaviours of the coach that influence athletes' regulation and ability to perform. As such, not only did coaches provide technical instruction and feedback to their athletes but also cues that facilitated athlete regulation to optimize their performance: "You have to find the right mindset and my coach sometimes was there to help me get that mindset. I would say it's important to have him around if I'm not in a good mindset" (Taylor). More specifically, athletes described how achieving a flow state was optimal for performance: "My goal in competition is to put your body on autopilot. You've practiced a dive so many times you just gotta let muscle memory do the work. If you start deviating from that, that's when you start getting in trouble" (Adrian). In fact, coaches played a 
role in helping athletes to adopt the right mindset which in turn, facilitated the achievement of a flow state:

Usually, I try to elevate my heart rate which is really uncomfortable. But sometimes, you need to feel a little more adrenaline to perform. So then, I'm like 'I feel weird. I'm not comfortable, I'm stressed. I don't know what to do.' And my coaches are like 'We have the presentation. Relax. Try to focus to get in the zone that you know.' Because when I feel a certain way, I know I can perform well. So they told me 'Go and get in your zone. Try to figure out how to get in your zone.' It wasn't $100 \%$ but I was maybe $75 \%$ in the zone that I wanted to be (Charlotte).

In some cases, to help athletes reach the optimal performance state, coaches calmed them down to deal with the pressures of this context:

In a competition, I think the role of the coach is partially to help us stay calm and to kind of remind us of our basics. Because in competition, our brains can go awry, they can get overwhelmed, and depending on the event, it's hard to focus. So I think the role of the coach would be to keep you calm, give you confidence, remind you why you're there, what you're doing, and that you've worked a lot to get there (Laura).

Additionally, athletes discussed the value of their coaches instilling confidence: "My coach is like 'You know what to do. You're capable of doing it. You got it.' So he makes you believe in yourself. That's a big thing" (Charlotte). In fact, this helped athletes believe in themselves: My adrenaline kicked in and I felt better and my coach was like 'You got this. Be positive. Believe in yourself.' I think that's one thing that my coach does that most other coaches I've had haven't done is telling me to believe in myself like 'You can do this. You could be the best in the world' rather than kind of cutting you down. So motivating 
me like that really helped me believe that I could do something with power and just kill it (Laura).

Athlete confidence also enabled them to stay focused while not overthinking and letting doubt settle in:

I'm someone who's very nervous. I doubt myself quite a lot in competition. Even though I did everything that I had to do in practice, even though all my practices are absolutely amazing, I'm always going to doubt myself. My coach is trying to break that. He really is putting me in a position where he makes me feel like I'm the king of the diving board (Taylor).

In fact, not only did coaches instill confidence in what they said to athletes, but also in how they behaved in competition:

My coach instills confidence physically. He walks with his head up, chin high. He's confident in everything, usually. Even if there's doubt, he'll portray confidence. As an athlete competitively, you gotta show confidence and sometimes for me, I've got to convince myself that I'm confident. He helps me do that (Mason).

At the Olympic Games, my coach looked at me when I was on the board and he put his hand on his heart. It was his way of saying do it for yourself and do it with pride. Be proud. Be proud. That was it. There's two words that my coach says a lot to me in competition and it's 'Be proud.' Those little things are to me, much more important than the technical aspect (Taylor). In sum, coaches appeared to play a role in helping athletes achieve ideal physical and mental states for optimal performance. This could be achieved by calming down the athlete, instilling confidence, and remaining positive. This highlights the importance of coaches being in 
tune with their athletes to know how to best respond and intervene in different situations for the athletes' benefit to achieve high levels of performance.

Game-day patterns. This theme encapsulates elements related to how athletes deal with the physical and mental aspects on game-day, and how these are influenced by coaching behaviours. As such, the context of competition came with its share of pressures and stressors to deliver successful performances:

World Championships is obviously the most important competition of the year. The ranking at the end will be what decides your next year. There's always more stress. The pressure is on. You kind of see that the coaches feel like everything at the Worlds or the World Cup kind of relies on them because it's also if their coaching was done properly. I think that also stresses them out because they want us to do well and really show that what we've been working on all year actually worked (Kate).

When I put too much pressure on myself, I start overthinking. The more we stick to our daily routine and the more we simulate our practices, the better it is for me. And I think my coach knows that and he tries to stick to that (Adrian).

In fact, athletes relied on different strategies such as having routines to deal with the stress and pressures of competition. Individualized routines helped athletes to be consistent, have reference points, normalize competition, prepare for a dive, avoid overthinking, and deal with distractions: Everybody has a certain routine in between dives and you just have to respect it. That's why it works. If you change that completely, you're not going to know what to do and you're going to get in your head. Then, the chances are that you're going to mess up. You're so used to doing that routine but if you break it, if you change it, it's gonna take a while to be able to find your reference points (Taylor). 
Typically, athlete routines consisted of seeing their coaches before and after all five or six of their dives during an event. More specifically, before hearing the whistle indicating their turn, some athletes received a final reminder from their coaches while they were at the top of the platform/springboard:

And then during competition, I'll be waiting listening to music and then 10 divers before my dive, I'll go see the coaches and I'll do a simulation. Then, my coaches give me my correction. It's kind of like a routine. After doing my simulation, my coaches will give me the same correction again, motivate me, and tell me to go up. Then, as we're up the stairs, usually, I look down and they'll tell me the same thing. Just remind me and give me the key points of what I need to do for the entry and the take off. Once I see that, I wait for the whistle and go (Laura).

I think having the kind of routine is the most important thing because once you're up there, when you see your coach at the bottom and he tells you, you still have a couple of minutes before doing the actual dive. You have time to start stressing before you get up there. Having the reminder the last second before the whistle actually blows, that's the last thing you think about. It's really what he tells you. To me, it's really the most important thing because it won't allow me to overthink anything (Kate).

Following their dive, each athlete went to see his/her coach and received feedback on the execution. Then, athletes carried on with their personal routines until the next round of dives, which typically ranged between 10 and 45 minutes: "After I dive, I'll go and get my correction of what I did good, what I did wrong. Then, I'll go and wait for my other dive and then repeat" (Laura). 
Considering athletes had personalized routines enabling them to perform to their full potential, coaches had to be aware of individual differences and adapt their approach with every athlete: "Coaches have to change how they coach from one athlete to another in competitions because it's so individual that we all have a different way of interpreting or competing and being emotional in a competition" (Mason). More specifically, coaches had the ability to adapt their coaching style based on their athletes' needs for optimal preparation and performance:

My coach's responsibility is to coach me. He's always going to be there for me, but he understands that I need my own space. I like to be alone. I don't want to talk to people. I don't want to have a chat with my coach. He's just gonna be there and if I need him, I'm going to go see him. I will talk to him but he understands that I need a bit of a distance and he respects that a lot (Taylor).

I think coaches' roles and responsibilities in competition are to accommodate the needs of the athlete. My coach has me and another diver. We're two completely different divers and we have different needs for competition. My coach is really good at knowing what we need and actually going by it (Adrian).

I was injured and I was having a really hard time. Nothing was working, even technical so it was really hard mentally. To have my coach's support mentally is what I needed most. I think that's one of the things that makes a good coach (Charlotte).

It was important for athletes to feel the support from their coaches on competition day. This support was demonstrated through encouragement: "In competition, we always give a little fist bump. That's more to encourage. It's more of a tradition" (Adrian). Coaches also demonstrated support in their presence, including their reactions to athlete performances: 
The value of my coach tapping me on the shoulder and saying 'move on' was his way to say we're together in this. I screwed up but we actually screwed up. It's a team thing. He was there for me from the beginning to the end of the event. He was there and even if I didn't do as well as we wanted to, he was still going to be there until the end (Taylor). Overall, athletes developed strategies (i.e., individualized routines) with their coaches to manage the stress and pressure associated with performing at the elite level. The effectiveness of such strategies relied in part on the coaches' ability to adapt to the needs of each individual athlete while also providing support in this context. 


\section{Chapter 5}

\section{Discussion}

The purpose of this study was to gain a better understanding of elite individual sport athletes' (i.e., divers) perspectives of their coaches' behaviours during competition, which included their desired coaching behaviours in this context. Effective coaching strategies and behaviours during competition affecting elite athlete performance has received a significant amount of empirical attention in the coaching science literature (Allain, Bloom, \& Gilbert, 2018; Gould, Greenleaf, Guinan, \& Chung, 2002; Mallett, 2005, 2010; Olusoga, Maynard, Hays \& Butt, 2012; Ritchie \& Allen, 2015). A large proportion of this literature has investigated the role and influence of the coach in team sports (Bloom, 1996; Donoso-Morales, Bloom, \& Caron, 2017a; Eccles \& Tran, 2012; Urquhart, Bloom, \& Loughead, in press), which does not account for contextual differences between sport types (i.e., length of competition, interactions with officials, etc.) (Aleksic-Veljkovic, Djurovic, Dimic, Mojanovic, \& Zivcic-Markovic, 2016; Baker, Yardley, \& Côté, 2003; Jowett, Paull, \& Pensgaard, 2005; Rhind, Jowett, \& Yang, 2012). The results of the current study indicated that elite divers perceived their coaches to play an essential role during competition by implementing various strategies that contributed to their performance. This was partly attributed to a strong coach-athlete relationship. This chapter will be divided into two sections. The first relates to the unique coach-athlete relationship and its influence on interactions. The second part will address coaches' strategies and behaviours in competition that contributed to athlete satisfaction and performance success.

\section{Coach-Athlete Relationship}

Although not specifically assessing the quality of the relationship between divers and coaches, findings of the current study demonstrated that different aspects of this relationship 
were central for effective athlete functioning. Athletes described forming a unique bond with their coaches, which mirrors the helpful and caring type of relationship previously identified as crucial for the success of elite sport athletes (Jowett \& Cockerill, 2003; Jowett \& Poczwardowski, 2007). According to Jowett (2007), the interdependence of the $3+1$ Cs constructs (i.e., closeness, commitment, complementarity, co-orientation) reflects the quality of the relationship. In turn, a quality relationship has resulted in numerous positive outcomes including higher levels of satisfaction with performance and personal treatment (Jowett \& Poczwardowski, 2007). Although athletes in the current study touched upon elements related to all of the constructs when discussing their relationship with coaches, the elements of closeness and co-orientation were described in more depth.

Closeness. Specifically related to the closeness construct of the coach-athlete relationship (Jowett, 2007), findings of the current study showed that athletes referred to their coaches as a close friend, mentor, or a father or mother figure (Jowett \& Cockerill, 2003; Philippe \& Seiler, 2006). Although previous studies have shown that a lack of closeness (i.e., feeling unattached, distant) was found to negatively affect athletes and the effectiveness of their relationship with coaches (Jowett \& Cockerill, 2003; Jowett \& Frost, 2007; Jowett \& Meek, 2000), athletes in the current study were more concerned with being too close to their coaches on a personal level, which was thought to lead to conflict. As such, athletes described the need to achieve a balanced relationship that would not interfere with their training and success. Similarly, other studies have suggested that boundaries (i.e., closeness on a personal level, emotional attachment) within the relationship were necessary for optimal functioning (Jowett, 2003; Philippe \& Seiler, 2006). Considering that elements related to closeness (i.e., trust, liking) have contributed more to the personal side of the relationship (Jowett, 2003; Jowett \& Cockerill, 2003), understanding 
athletes' preferences related to closeness may inform and help coaches to understand elements to focus on to achieve a balance in the personal and professional relationship for optimal functioning.

An element of the relationship that appeared to be of crucial importance for athletes in this study was trust. Trust is one of the components reflecting the closeness construct of the 3+1Cs model that conceptualizes the coach-athlete relationship (Jowett, 2005; Jowett, 2007; Jowett \& Meek, 2000; Jowett \& Timson-Katchis, 2005). Athletes trusted their coaches' ability to develop their potential by making decisions with their best interests in mind, especially in competition. More specifically, a trusting relationship helped athletes perform their different dives at various heights by helping them overcome any fear or indecisions. Along the same line, considering the proprioceptive nature of the sport in which the accuracy of athletes' feeling in the air may vary, athletes put a lot of trust in the feedback of their coaches, thus enabling athletes to make the right adjustments to their technique to improve the performance of their dives. Trust was also found to open lines of communication between the coach and athlete due to the level of comfort athletes expressed in sharing their concerns with coaches. Although research has alluded to aspects of the coach-athlete relationship across various individual sports (i.e., swimming, kayak, wrestling; Trzaskoma-Bicserdy, Bognar, Revesz, \& Geczi, 2007), the current findings suggested that characteristics of diving may have influenced the importance of certain elements of the relationship for optimal functioning and athlete development. Findings extend the literature on the coach-athlete relationship by showing the importance of trust in a high-risk sport, which supports the need to take the context in which the relationship develops into consideration for optimal functioning (Lorimer \& Jowett, 2014; Poczwardowski, Barott, \& Henschen, 2002). This is important considering how trust-related issues have been found to 
negatively influence athletes leading up to the Olympics (Gould, Guinan, Greenleaf, Medbery, \& Peterson, 1999).

Co-orientation. The construct of co-orientation represents the interdependence between the closeness, commitment, and complementarity constructs of the model (Jowett, 2007). More specifically, it represents the level of understanding and similarity between the coach and athlete while considering their interpersonal perspectives (Jowett, 2009). Findings of the current study are described from the athletes' perspective in relation to their coaches, which represents the meta-perspective (Jowett, 2009). The meta-perspective refers to the perceptions of how athletes believe their partner feels, acts, and thinks in regards to the relationship and was used to capture the construct of co-orientation within this dynamic (Jowett, 2009). As such, athletes in the current study described how they felt their coaches cared for them by putting their needs first, liked them, understood them, and supported them in order to excel on game day. For example, athletes perceived their coaches to want them to succeed because they cared for them as athletes rather than being involved in the process for their own personal motives (i.e., status associated with having successful athletes at this level). In turn, this made athletes feel as though they had full support from their coaches, which was identified as crucial when competing to make athletes feel confident. Considering how positive meta-perspectives of the relationship have been quantitatively assessed and linked to positive personal and interpersonal benefits (i.e., goal adoption, motivation; satisfaction) (Adie \& Jowett, 2010; Jowett, 2009), findings of the current study contribute to a qualitative and in-depth understanding of how athletes' meta-perspectives of their relationship with their coaches may facilitate performance success. Further exploring what contributes to these positive views and how they link to positive outcomes such as performance through qualitative methods may help coaches and athletes gain an in-depth 
understanding of the process involved in developing this aspect of the relationship.

Within co-orientation lies the concept of understanding, including empathic understanding, which involves a comparison between one's own meta-perspective compared to the other's direct-perspective (Lorimer \& Jowett, 2012). More specifically, empathic understanding reflects the ability of coaches and athletes to accurately infer their partners' thoughts, feelings, and behaviours toward himself or herself (Lorimer \& Jowett, 2012). In the current study, this level of understanding was achieved by the amount of time coaches and athletes spent together during training, competition, and travelling. Consequently, coaches came to understand how athletes reacted in different situations and to various phases of training and competition, which athletes said took a long time to achieve. More specifically, athletes believed that coaches had to take the time to get to know them as individuals before being able to understand their feelings and actions. Additionally, in the context of competition, athletes described a trial and error process with their coaches to find what worked best for them to perform to the best of their abilities. As such, it may have taken coaches a while to understand to what extent an athlete wanted to talk to them during competition. Although findings of the current study suggest that having a relationship of longer duration would help athletes achieve levels of understanding that facilitate their interactions, previous findings have suggested that athletes who had been with their coaches for longer periods had lower levels of understanding (Jowett \& Clark-Carter, 2006). This was attributed to the fact that coaches and athletes in relationships of longer duration had the tendency to make assumptions when inferring their thoughts, feelings, and emotions (Jowett \& Clark-Carter, 2006). Similar inconsistencies have been found in the literature when linking elements related to the concept of understanding with relationship outcomes (Sillars, 1985; Sillars \& Scott, 1983). Considering the difference in 
findings and the complexity of dyadic relationships, more research is needed to further explore the mediating role of relationship length in the development and maintenance of co-orientation (Jowett, 2009; Jowett \& Clark-Carter, 2006; Thomas \& Fletcher, 2003).

Additionally, a perspective reflecting the ability to understand the other from moment-tomoment reflects a different perspective of co-orientation called empathic accuracy (Ickes, Stinson, Bissonnette, \& Garcia, 1990; Lorimer \& Jowett, 2012). Although empathic understanding allows for a general understanding between coaches' and athletes' perspectives of each other regarding the quality of the relationship, it fails to assess their ability to understand each other in specific moments (Ickes, Gesn, \& Graham, 2000; Ickes et al., 1990; Lorimer \& Jowett, 2012). Athletes in the current study described their appreciation for coaches' ability to know when to motivate them, when they were feeling down, tired, sore, or stressed in competition. For example, an athlete described a time where the pressure of competition was present, resulting in the athlete feeling stressed and uncomfortable. The coach recognized this and provided the athlete with elements to focus on while reminding the athlete of strategies to help stay calm. Additionally, athletes shared moments of coaches' knowing the right things to say to make the athlete feel confident or motivated, especially after unsuccessfully performing a dive in competition. To date, studying coaches' and athletes' ability to understand each other moment-to-moment has been primarily explored in the context of training (Lorimer \& Jowett, 2009a, 2009b, 2010, 2011). Considering how certain competitive events represent defining moments in athletes' careers (Gould et al., 2002; Gould \& Maynard, 2009), it is of particular relevance to understand how coaches' ability to infer athletes' thoughts and feelings in these critical moments may help them support athletes in managing these situations. Consequently, findings of the current study extend the literature by supporting the need to develop empathic 
accuracy for coaches to successfully be able to understand how athletes feel in specific moments during competition and the influence this may have on athlete performance.

Considering the importance of developing an understanding for optimal functioning, it is important to explore factors that may contribute to enhancing the construct of co-orientation. Athletes in the current study described how optimal levels of understanding depended in part on effective communication. More specifically, athletes perceived how communicating performance goals prior to competition helped to remind them of what to focus on while enabling them to shape their own expectations with regards to their performance. Athletes believed it was essential to tell their coaches how they felt in terms of energy and stress levels so their coaches could help manage their emotions. However, athletes also described instances in which communication was less effective, subsequently influencing levels of understanding and interactions between their coaches. For example, athletes described instances where they did not understand the technical instruction communicated by their coach. Consequently, it was difficult for athletes to apply the changes which resulted in feelings of frustration for both the coach and athlete. Similarly, communication is thought to prevent the escalation of potential conflicting situations through the achievement of shared knowledge (i.e., self-disclosure, frequent communication, information exchange) and understanding of each other (i.e., common goals, intuitive communication) (Jowett \& Cockerill, 2003; Jowett \& Frost, 2007; Jowett \& Meek, 2000). Although communication has been found to clarify expectations and avoid distractions in competition (Donoso-Morales, Bloom, \& Caron, 2017b), findings of the current study also illustrate its purpose in diving competitions. This is of particular relevance considering how misunderstandings can lead to interpersonal conflict (Gould et al., 1999; Heelis, Caron, \& Bloom, 2020; Jowett \& Shanmugam, 2016). As a result, coaches and athletes are encouraged to 
familiarize themselves with the COMPASS model (Conflict management, Openness, Motivation, Positivity, Advice, Support, Social networks) of communication, which consists of guidelines to improve relationships and facilitate interactions (Jowett \& Shanmugam, 2016; Rhind \& Jowett, 2012). Exposure to this model may assist coaches and athletes to understand how these strategies could be applied in the specific context of competition.

\section{Coaching Strategies and Behaviours}

Athletes in the current study relied on coach input between dives in competition to direct their attention, prevent doubt from settling in, and manage emotions. More specifically, coaches provided regular technical instruction and feedback in the form of key words related to elements enabling athletes to perform the dive well during breaks in competition. While athletes were at the end of the platform or tower, having those key words readily available in their mind helped them to avoid becoming overwhelmed. This contrasts findings of coaches in other individual sport (i.e., gymnastics, track and field) who provided limited feedback to their athletes in competition due to the fear of overloading athletes with technical information (Côté, Salmela, \& Russell, 1995; Ritchie \& Allen, 2015). As such, expert gymnastics coaches gave minimal technical feedback to their athletes prior to competition while making no intervention attempts during an event (Côté et al., 1995). Although discrepancies in feedback provided may be partly due to the differences in the structure of competitive events, divers in the current study appreciated coach feedback and instruction in competition since it served as a reminder of familiar key elements that helped them to dive effectively by giving them something specific to focus on prior to their dive. Further exploring how athletes make use of technical feedback and instruction in competition may contribute to understanding the effectiveness of its implementation, thus complementing research on types of feedback (i.e., internal, external, 
proximal, distal) that have been found to facilitate individual sport performance (Bell \& Hardy, 2011; Halperin, Chapman, Martin, Abbiss, \& Wulf, 2016).

Thus far, developing an understanding of athletes has been discussed in relation to the quality of the coach-athlete relationship. Thus far, understanding athletes has been discussed However, this understanding may also be due to coaches' abilities to adapt their behaviours to each individual athlete, thus demonstrating emotional intelligence (Mallett \& Lara-Bercial, 2016; Urquhart et al., in press), which has been used to frame coaches' interpersonal knowledge in the high-performance sport environment (Chan \& Mallett, 2011; Gilbert \& Côté, 2013). According to Côté and Gilbert (2009), interpersonal knowledge includes coaches' social skills that influence the effectiveness of their athlete interactions. As such, this partly depends on coaches' ability to identify, use, understand, and manage athletes' emotions, which is all part of their emotional intelligence (Mayer \& Salovey, 2997). More specifically, according to Mayer and Salovey (1997), emotional intelligence is conceptualized by a developmental hierarchy that moves from a baseline level of perceiving emotions, through increasingly sophisticated levels that include using emotions to facilitate thought, to understand emotions, and to manage emotions. In fact, athletes in the current study described instances when coaches helped them manage emotions in the context of competition by understanding their athletes' mental and physical states (i.e., stress, fatigue, injury) to shape an appropriate response. Despite contextual differences in sport type (i.e., individual versus team), this notion parallels the way in which highly successful university level ice hockey coaches managed intermissions during a game (Allain et al., 2018). For example, ice hockey coaches adjusted the content and delivery of their intermission message given to athletes based on various factors including players' behaviours and emotions (i.e., player's mood, body language, interactions) (Allain et al., 2018). In fact, ice hockey coaches 
have successfully identified the content and intensity of players' emotional states (Hanin, 2003).

However, coaches in the current study were mainly concerned with adapting their behaviours to the benefit of each individual athlete rather than on a collective level. Thus, findings of the current study may contribute to enhancing individual sport coaches' interpersonal knowledge by informing them of factors to take into consideration to effectively shape their responses in competition.

Although emotional intelligence provides insight into the influence of affective processes between coaches and athletes, this fails to identify specific strategies used to influence and regulate athletes' emotions (Braun \& Tamminen, 2020). As such, athletes have been shown to regulate their own emotions (Hanin, 2000, 2007; Uphill, McCarthy, \& Jones, 2009). However, emotional regulation has been identified as inherently social in which one can deliberately attempt to influence the emotions of another person (Niven, Totterdell, \& Holman, 2007). Specifically, this concept can be understood through a process called emotional contagion, which refers to a "process in which a person or group influences the emotions or behaviour of another person or group through the conscious or unconscious induction of emotion states and behavioural attitudes" (Shoenewolf, 1990, p. 50). In fact, athletes in the current study described instances in which their coaches' emotions matched their own. For example, when coaches displayed excitement, athletes described feeling more upbeat. In some cases, the opposite also occurred where coaches had lower energy levels or displayed negative emotions such as frustration, which subsequently influenced the athlete. Some athletes described attempting to avoid getting distracted by coaches in these situations, which depended in part on athletes' ability to block this information out. Considering that most research has focused on emotional contagion between teammates in a group setting (Moll, Jordet, \& Pepping, 2010; O'Neill, 2008; 
Totterdell, 2000) or between opponents (Kerr \& Grange, 2009; Lanzetta \& Englis, 1989; Ronglan, 2007; Shapcott, Bloom, \& Loughead, 2007), findings of the current study illustrate how this process occurs on a one-on-one basis between a coach and athlete. Further understanding the influence of emotional contagion on individual behaviour is important considering that athletes have identified their coaches' states from various verbal and behavioural cues with ease, subsequently influencing athletes' cognitions (Thelwell, Wagstaff, Rayner, Chapman, \& Barker, 2017). Therefore, it is crucial for coaches to become aware of how their behaviours and appearance may influence athletes specifically in high-pressure situations. Although coaches' expressions and behaviours have the potential to positively influence athletes in the context of competition, there were also instances in which athletes discussed the challenges in coping with certain emotions displayed by the coach. Examples of such emotions included when athletes felt as though their coaches were frustrated, disappointed, or were giving up because of less desirable performance outcomes. Athletes described how these instances made it difficult to stay focused and motivated to perform the remaining dives in the competition. Findings relate to the concept of interpersonal conflict in which interdependent parties experience negative emotional reactions to perceived disagreements and interference with the attainment of their goals (Barki \& Hartwick, 2004). In fact, interpersonal conflict has led to cognitive, affective, and behavioural consequences (i.e., disagreement, anger, upset, loss in concentration) in the context of competition (Barki \& Hartwick, 2004; Mellalieu, Shearer, \& Shearer, 2013). Considering the negative outcomes associated with negative feelings (Fletcher, Hanton, Mellalieu, \& Neil, 2012; Mellalieu et al., 2013; Olusoga et al., 2012), further knowledge related to how individuals experience interpersonal conflict in sport is warranted (Wachsmuth, Jowett, \& Harwood, 2017). Therefore, current findings further contribute to the understanding of 
the affective consequences of specific emotions expressed by diving coaches in competition.

Finally, the results of the current study revealed that athletes developed routines with their coaches throughout the day of competition that helped them deal with pressure and stress related to this context. This finding parallels previous literature supporting the use of developed routines by athletes to facilitate optimal performance (Gould, Greenleaf, Guinan, Dieffenbach, \& McCann, 2001; Gould \& Maynard, 2009; Grant \& Schempp, 2014; Greenleaf, Gould, \& Dieffenbach, 2001), yet extends this line of research by illustrating individual sport athletes' perceptions of their coaches' role and involvement in their routines. For instance, athletes in the current study valued consistent interactions with their coaches before and after each of their five or six dives during an event as these moments helped them to normalize competition and prepare for a dive while avoiding distractions. These planned and recurring interactions that took place during a diving competition differed in frequency, duration, and occurrence in comparison to those that occur in other team and individual sports partly due to the structure of the competitive event (Allain et al., 2018; Côté et al., 1995; Grant \& Schempp, 2014; Mallett, 2005; Rhind et al., 2012; Ritchie \& Allen, 2015). For example, in comparison to other individual sports (Côté et al., 1995; Ritchie \& Allen, 2015), interactions between divers and coaches were an integral part of their routines because they always occurred at a specific moment. In contrast, track and field Olympic and Paralympic coaches have identified the challenge of knowing when and how to appropriately intervene with their athletes since interactions were not planned ahead of time (Ritchie \& Allen, 2015). This differs from the current results where the athletes expected and appreciated having regular interactions with their coaches over the course of the entire competition day (lasting anywhere from 5-10 hours). Furthermore, in comparison to team sports where game-day routines were found to be mainly designed and led by coaches (Allain et al., 
2018; Bloom, Durand-Bush, \& Salmela, 1997; Bloom \& Salmela, 2000), routines in the current study were mainly shaped by the athletes and required coaches to adjust and respect these individualized routines. For example, some athletes wanted to receive a reiteration of coach instruction moments before performing their dive in competition while up on the springboard/platform to prevent distractions. Considering how unsuccessful performances have been in part attributed to coaches and athletes deviating from routines in competition (Gould et al., 1999), findings of the current study may help coaches and athletes become aware of each member's role in creating and implementing routines on game-day and between breaks in competition while illustrating the particular value athletes attribute to this strategy in contributing to facilitating their performance. 


\section{Chapter 6}

\section{Summary}

The context of competition is one place where the behaviours of the coach have the potential to influence athletes' performance and success (e.g., Allain, Bloom, \& Gilbert, 2018; Bloom, Falcão, \& Caron, 2014; Côté \& Gilbert, 2009; Gould, Greenleaf, Guinan, \& Chung, 2002; Mallett, 2005, 2010; Olusoga, Maynard, Hays, \& Butt, 2012; Vallée \& Bloom, 2005). Various factors have contributed to coaching effectiveness during competition, such as having well-developed routines (Allain et al., 2018; Côté, Salmela, \& Russell, 1995), effective communication skills (Allain et al., 2018; Bloom \& Salmela, 2000; Halperin, Chapman, Martin, Abbiss, \& Wulf, 2016), the ability to read athletes' emotional states (Chan \& Mallett, 2011; Laborde, Dosseville, \& Allen, 2016), and managing their own emotions (Donoso-Morales, Bloom, \& Caron, 2017a; Olusoga et al., 2012). While a lot of research has explored coaching strategies in the context of team sports (Allain et al., 2018; Bloom, Durand-Bush, \& Salmela, 1997; Gould, Guinan, Greenleaf, Medbery, \& Peterson, 1999; Greenleaf, Gould, \& Dieffenbach, 2001; Stein, Bloom, \& Sabiston, 2012), differences in coach and athlete interactions in individual sports suggest that more research is required to better understand this unique context (Rhind, Jowett, \& Yang, 2012; Salminen \& Liukkonen, 1996). Therefore, the purpose of the study was to gain a better understanding of elite individual sport athletes' (i.e., divers) perspectives of their coaches' behaviours during competition, which included their desired coaching behaviours in this context.

Upon approval from the McGill Research Ethics Board, six athletes (3 males, 3 females) currently on the Canadian national diving team were interviewed for this qualitative study. This purposefully selected sample included three athletes who specialized in platform events and three 
who competed in springboard events. All athletes competed in both individual and synchronized events at the international level. Their combined experiences included participating in the sport for a range of 15 to 24 years, being members of the Canadian national diving team for 7 to 15 years, receiving a total of 42 medals at various international competition (i.e., Olympic World Championships, Commonwealth Games, and PanAmerican Games). All athletes had competed at a World Championship with four of the six athletes having made at least one appearance at an Olympic Games. Throughout their careers, athletes had between two to five coaches while being with their current coach between four and eleven years. These characteristics demonstrate the extensive experience and success of these athletes competing at the elite level.

The current qualitative study used a collective case study methodology to explore athletes' experiences with their coaches in the context of competition to gain an in depth understanding of the topic (Sparkes \& Smith, 2014). Semi-structured open-ended individual interviews were used to explore the participants' stories, accounts, reports, and descriptions about their perspectives, insights, experiences, feelings, emotions, and behaviours in relation to the research questions through conversation (Smith \& Sparkes, 2016). Interviews were transcribed verbatim and analyzed using a thematic analysis. Thematic analysis minimally organizes and describes the data collected in rich detail by identifying, analyzing, interpreting, and reporting patterns (Braun \& Clarke, 2013).

The current analysis revealed three overarching themes from the data: background and characteristics, coach-athlete relationship, and coaching strategies and behaviours. First, the overarching theme background and characteristics included experiences and characteristics of athletes and coaches contributing to their behaviours and success. Second, coach-athlete relationship related to the positive and negative factors of the relationship influencing all facets 
of their partnership. Thirdly, coaching strategies and behaviours involved strategies and behaviours used by coaches that influence how their athletes cope with and perform during competition. The three overarching themes will be presented in more detail in the following section.

\section{Conclusions}

\section{Background and Characteristics}

- Athletes' personal characteristics included passion for the sport, a strong work ethic, being autonomous, perseverant, and a strong desire to improve.

- Athletes felt their coaches held them to high standards.

- Athletes described key characteristics of their coaches such as a passion for the sport and ability to manage emotions.

\section{Coach-Athlete Relationship}

- Athletes described forming a unique bond with their coaches and referred to them as friends, family, or parent figure.

- Key features of this partnership included coaches believing, trusting, caring, and supporting their athletes.

- The development of trust allowed athletes to have confidence in their coaches' instruction and feedback.

- A balance in closeness between coaches and athletes was considered necessary for athletes and coaches to function effectively together.

- Coach and athlete challenges stemmed from a lack of understanding which depended in part on communication. 
- Athletes were influenced by coaches' emotions, energy, and attitudes in competition and interpreted these elements differently.

- Athletes struggled in instances where they felt their coaches were frustrated, disappointed, or were giving up on them.

\section{Coaching Strategies and Behaviours}

- Optimal athlete performance occurred when coaches and athletes were on the same page and when coaches understood how athletes responded to different phases of training and competition.

- Key words directed athletes' attention to the task, prevented them from overthinking, and helped them to manage emotions between rounds in competition.

- Coaches facilitated athlete regulation which included calming athletes down to facilitate the achievement of a flow state in order to deal with the pressures of the context of competition.

- Coaches instilled confidence in their athletes during competition by making them believe in themselves which enabled them to stay focused, not overthink, and avoid letting doubt settle in.

- Athletes relied on different strategies such as having individualized routines during competition day and seeing their coach before and after all of their dives to receive feedback and instruction.

- Athletes needed to feel the support from their coaches on competition day demonstrated through encouragement, their presence, and their reactions to athlete performance. 


\section{Practical Applications}

The current study is among the first to explore desired coaching behaviours from elite divers during competitions. The results from this study add to the research on effective coaching in this specific context by providing insight into athletes' perspectives of the effectiveness of various coaching strategies implemented in competition.

First, the results of the current study revealed that different aspects of this relationship were central for effective athlete functioning. More specifically, athletes described the need to achieve a balance in closeness with their coaches in terms of the personal and professional relationship. As such, having certain boundaries (i.e., closeness on a personal level, emotional attachment) was considered to be necessary for optimal functioning. Second, having trust in their coaches was found to be of particular importance for divers, especially if they had to make adjustments to their technique to improve their dives. Third, athletes described their appreciation for coaches' ability understand them in specific situations which was highlighted by coaches' ability to know when and how to motivate them. Fourth, optimal levels of understanding were found to depend in part on effective communication. However, instances where communication was less effective resulted in impaired levels of understanding between members, subsequently influencing their interaction which were accompanied by frustrations by coaches and athletes. Coaches were also found to provide regular technical instruction and feedback to athletes in the form of key words which was perceived to help athletes direct their attention, prevent doubt from settling in, and manage emotions associated with the pressures of this context. Fifth, athletes described instances in which lower energy levels or negative emotions were displayed by coaches influenced their focus and motivation. Lastly, results revealed that athletes developed routines with their coaches throughout the day of competition that helped them deal with 
pressure and stress related to this context. Routines were mainly shaped by athletes and required coaches to adjust and respect these individualized routines for optimal performance. Therefore, findings may help coaches to understand their role in creating and implementing athlete routines on game-day and between break during competition based on athlete preferences related to this strategy.

\section{Limitations and Recommendations}

While the current study provided insight into the desired coaching behaviours of elite divers in competition, several limitations must be taken into consideration. First, results may only be applicable to athletes involved in individual sports of similar competition structure (i.e., boxing, moguls, snowboarding, weight lifting, gymnastics) in which intermittent breaks occur during competition allowing for coaches and athletes to interact during these times. Second, the results are only representative of the perceptions of athletes and not those of coaches. Future research could include perceptions of both the coach and athlete to gain insight into the congruence of their perspectives, especially with regards to concepts such as mutual understanding and emotional intelligence. Third, findings are limited by athletes' ability to recall events and perhaps influenced by the timing of the season at which the interviews occurred. Interviews occurred in the fall at the beginning of the season. Perhaps future research could interview athletes at the end of the season allowing them time for reflection. Fourth, both males and females were included in the sample while not specifically attempting to identify differences between genders. Therefore, future research could consider exploring whether gender differences exist when it comes to desired coaching behaviours in this context. Differences associated with coach-athlete dyads of different gender combinations could also be explored considering that satisfaction with training and instruction have been observed (Jowett \& Nezlek, 2011). Fifth, 
participants in this study had been diving for a range of 15 to 24 years while being members of the Canadian national diving team for 7 to 15 years. Therefore, findings may not be transferable to less experienced or younger athletes considering that coaching differences exist in this coaching context (Côté \& Gilbert, 2009). Lastly, athletes in this study had between two to five coaches while being with their current coaches between four and eleven years. Therefore, this should be considered when transferring the results in other sport contexts considering that number of years being with a coach influences the development of coach-athlete relationships (Jowett, 2008). 


\section{References}

Abraham, A., Collins, D., \& Martindale, R. (2006). The coaching schematic: Validation through expert coach consensus. Journal of Sports Sciences, 24, 549-564.

Adie, J. W., \& Jowett, S. (2010). Meta-perceptions of the coach-athlete relationship, achievement goals, and intrinsic motivation among sport participants. Journal of Applied Social Psychology, 40, 2750-2773.

Aleksic-Veljkovic, A., Dimic, I., Mujanovic, R., \& Zivcic-Markovic, K. (2016). College athletes' perceptions of coaching behaviours: Differences between individual and team sports. Baltic Journal of Sport \& Health Sciences, 101, 61-65.

Allain, J., Bloom, G. A., \& Gilbert, W. D. (2018). Successful high-performance ice hockey coaches' intermission routines and situational factors that guide implementation. The Sport Psychologist, 32, 210-219.

Anderson, J. R. (1982). Acquisition of a cognitive skill. Psychological Review, 89, 369-406.

Baker, J., Côté, J., \& Hawes, R. (2000). The relationship between coaching behaviours and sport anxiety in athletes. Journal of Science and Medicine in Sport, 3, 110-119.

Baker, J., Yardley, J., \& Côté, J. (2003). Coach behaviours and athlete satisfaction in team and individual sports. International Journal of Sport Psychology, 34, 226-239.

Barki, H., \& Hartwick, J. (2004). Conceptualizing the construct of interpersonal conflict. The International Journal of Conflict Management, 15, 216-244.

Becker (2009). It's not what they do, it's how they do it: Athlete experiences of great coaching. International Journal of Sports Science \& Coaching, 4, 93-119.

Bell, J. J., \& Hardy, J. (2009). Effects of attentional focus on skilled performance in golf. Journal of Applied Sport Psychology, 21, 163-177. 
Bloom, G. A. (1996). Competition: Preparing for and operating in competition. In J. H. Salmela (Ed.), Great job coach! Getting the edge from proven winners (pp. 138-179). Ottawa, Ontario: Potentium.

Bloom, G. A., Durand-Bush, N., \& Salmela, J. H. (1997). Pre- and postcompetition routines of expert coaches of team sports. The Sport Psychologist, 11, 127-141.

Bloom, G. A., Falcão, W. R., \& Caron, J. G. (2014). Coaching high performance athletes: Implications for coach training. In A. R. Gomes, R. Resende, \& A. Albuquerque (Eds.), Positive human functioning from a multidimensional perspective: Promoting high performance (Vol. 3, pp. 107-132). New York, NY: Nova Science.

Bloom, G. A., \& Salmela, J. H. (2000). Personal characteristics of expert team sport coaches. Journal of Sport Pedagogy, 6, 56-76.

Braun, V., \& Clarke, V. (2013). Successful qualitative research: A practical guide for beginners. Thousand Oaks, CA: Sage.

Braun, C., \& Tamminen, K. A. (2019). Coaches' interpersonal emotion regulation and the coachathlete relationship. Movement Sport Sciences, 3, 37-51.

Chan, J. T., \& Mallett, C. J. (2011). The value of emotional intelligence for high performance coaching. International Journal of Sport Science and Coaching, 6, 315-328.

Collinson, V. (1996). Proceedings from the Annual Meeting of the Japan-United States Teacher Education Consortium: Becoming an exemplary teacher: Integrating professional, Interpersonal, and intrapersonal knowledge. Naruto, Japan: Eric.

Côté, J., Bruner, M., Strachan, L., Erickson, K., \& Fraser-Thomas, J. (2010). Athletes' development and coaching. In J. Lyle \& C. Cushion (Eds.), Sport coaching: Professionalization and practice (pp. 63-84). Oxford, UK: Elsevier. 
Côté, J., \& Gilbert, W. D. (2009). An integrative definition of coaching effectiveness and expertise. International Journal of Sports Science \& Coaching, 4, 307-323.

Côté, J., Salmela, J. H., \& Russell, S. J. (1995). The knowledge of high-performance gymnastic coaches: Competition and training considerations. The Sport Psychologist, 9, 76-95.

Côté, J., Salmela, J. H., Trudel, P., Baria, A., \& Russell, S. (1995). The Coaching Model: A grounded assessment of expert gymnastic coaches' knowledge. Journal of Sport and Exercise Psychology, 17, 1-17.

Creswell, J. W. (2013). Qualitative inquiry and research design: Choosing among five approaches (3rd ed.). Thousand Oaks, CA: Sage.

Cushion, C. J., Armour, K., \& Jones, R. (2006). Locating the coaching process in practice: Models “for” and "of” coaching. Physical Education and Sport Pedagogy, 11, 83-99.

Daly, K. (2007). Qualitative methods for family studies and human development. Thousand Oaks, CA: Sage.

Davis, L., \& Jowett, S. (2014). Coach-athlete attachment and the quality of the coach-athlete relationship: implications for athlete's well-being. Journal of Sports Sciences, 32, 14541464.

Davis, L., Jowett, S., \& Lafrenière, M.-A. K. (2013). An attachment theory perspective in the examination of relational processes associated with coach-athlete dyads. Journal of Sport and Exercise Psychology, 35, 156-167.

Debanne, T., \& Fontayne, P. (2009). A study of a successful experienced elite handball coach's cognitive processes in competition situations. International Journal of Sports Science \& Coaching, 4, 1-16. 
Donoso-Morales, D., Bloom, G. A., \& Caron, J. G. (2017a). Creating and sustaining a culture of excellence: Insights from accomplished university team-sport coaches. Research Quarterly for Exercise and Sport, 88, 503-512.

Donoso-Morales, D., Bloom, G. A., \& Caron, J. G. (2017b). Canadian university coaches’ perceptions on the importance of effective planning and comunication skills. CienciAmérica: Revista de Divulgación Científica de la Universidad Tecnológica Indoamérica, 6, 11-16.

Duchesne, C., Bloom, G. A., \& Sabiston, C. M. (2011). Intercollegiate coaches' experiences with elite international athletes in an American sport context. International Journal of Coaching Science, 5, 49-68.

Duke, A., \& Corlett, J. (1992). Factors affecting University women's basketball coaches' timeout decisions. Canadian Journal of Sport Sciences, 17, 333-337.

Eccles, D. W., \& Tran, K. B. (2012). Getting them on the same page: Strategies for enhancing coordination and communication in sports teams. Journal of Sport Psychology in Action, $3,30-40$.

Feltz, D. L., \& Chase, M. A. (1998). The measurement of self-efficacy and confidence in sport. In J. L. Duda (Ed.), Advancements in sport and exercise psychology measurement (pp. 63-78). Morgantown, WV: Fitness Information Technology.

Fletcher, D., Hanton, S., Mellalieu, S. D., \& Neil, R. (2012). A conceptual framework of organizational stressors in sport performers. Scandinavian Journal of Medicine and Science in Sports, 22, 545-557. 
Fletcher, D., \& Scott, M. (2010). Psychological stress in sports coaches: A review of concepts, research, and practice. Journal of Sports Sciences, 28, 127-137.

Gilbert, W. D., \& Côté, J. (2013). Defining coaching effectiveness: A focus on coaches’ knowledge. In P. Potrac, W. Gilbert, \& J. Denison (Eds.), Routledge handbook of sports coaching (pp. 147-159). London: Routledge.

Gilbert, W. D., \& Trudel, P. (2004). Role of the coach: How model youth team sport coaches frame their roles. The Sport Psychologist, 18, 21-43.

Gilbert, W. D., Trudel, P., \& Haughian, L. P. (1999). Interactive decision making factors considered by coaches of youth ice hockey during games. Journal of Teaching in Physical Education, 18, 290-311.

Gould, D., Greenleaf, C., Guinan, D., \& Chung, Y. (2002). A survey of U.S. Olympic coaches: Variables perceived to have influenced athlete performances and coach effectiveness. The Sport Psychologist, 16, 229-250.

Gould, D., Greenleaf, C., Guinan, D., Dieffenbach, K., \& McCann, S. (2001). Pursuing performance excellence: Lessons learned from Olympic athletes and coaches. Journal of Excellence, 4, 21-43.

Gould, D., Guinan, D., Greenleaf, C., Medbery, R., \& Peterson, K. (1999). Factors affecting Olympic performance: Perceptions of athletes and coaches from more and less successful teams. The Sport Psychologist, 13, 371-394.

Gould, D., \& Maynard, I.W. (2009). Psychological preparation for the Olympic Games. Journal of Sports Sciences, 27, 1393-1408. 
Grant, M. A., \& Schempp, P. (2014). Elements of success: Olympic swimming gold medalists' understanding of their competition-day routines. International Journal of Sports Science \& Coaching, 9, 287-306.

Greenleaf, C., Gould, D., \& Dieffenbach, K. (2001). Factors influencing Olympic performance: Interviews with Atlanta and Nagano US Olympians. Journal of Applied Sport Psychology, 13, 154-184.

Halperin, I., Chapman, D. W., Martin, D. T., Abbiss, C., \& Wulf, G. (2016). Coaching cues in amateur boxing: An analysis of ringside feedback provided between rounds of competition. Psychology of Sport and Exercise, 25, 44-50.

Hanin, Y.L. (2000). Emotions in sport. Champaign, IL: Human Kinetics.

Hanin, Y. L. (2003). Performance related emotional states in sport: A qualitative analysis. Forum: Qualitative Sozial Research, 4, 1-31.

Hanin, Y. L. (2007). Emotions in sport: Current issues and perspectives. In G. Tenenbaum \& R. C. Eklund (Eds.), Handbook of sport psychology (3rd ed.) (pp. 33-58). Hoboken, NJ: John Wiley \& Sons.

Heelis, W. J., Caron, J. G., \& Bloom, G. A. (2020). The experiences of high-performance coaches in the management of difficult athletes. Psychology of Sport \& Exercise, 51, 101751.

Hodge, K., Henry, G., \& Smith, W. (2014). A case study of excellence in elite sport: Motivational climate in a world champion team. The Sports Psychologist, 28, 60-74. Huff, A. S. (2009). Designing research for publication. Los Angeles, CA: Sage. Ickes, W., Gesn, P. R., \& Graham, T. (2000). Gender differences in empathic accuracy: Differential ability or differential motivation? Personal Relationships, 7, 95-109. 
Ickes, W., Stinson, L., Bissonnette, V., \& Garcia, S. (1990). Naturalistic social cognition: Empathic accuracy in mixed-sex dyads. Journal of Personality and Social Psychology, $59,730-742$.

Jackson, B., Dimmock, J., Gucciardi, D., \& Grove, J. (2010). Relationship commitment in athletic dyads: Actor and partner effects for big five self-and-other ratings. Journal of Research in Personality, 44, 641-648.

Jackson, B., Grove, J. R., \& Beauchamp, M. R. (2010). Relational efficacy beliefs and relationship quality within coach-athlete dyads. Journal of Social and Personal Relationships, 27, 1035-150.

Jowett, S. (2003). When the "honeymoon" is over: A case study of a coach-athlete dyad in crisis. The sport psychologist, 17, 444-460.

Jowett., S. (2005). On repairing and enhancing the coach-athlete relationship. In S. Jowett \& M. Jones (Eds.), The psychology of coaching: Sport and exercise psychology division (pp. 14-26). Leicester, UK: The British Psychological Society.

Jowett, S. (2007). Interdependence analysis and the $3+1 \mathrm{Cs}$ in the coach-athlete relationship. In S. Jowett \& D. Lavallee (Eds.), Social psychology in sport (pp. 15-27). Champaign, IL: Human Kinetics.

Jowett, S. (2008). Moderators and mediators of the association between the coach-athlete relationship and physical self-concept. International Journal of Coaching Science, 2, 4362.

Jowett, S. (2009). Validating coach-athlete relationship measures with the nomological network. Measurement in Physical Education and Exercise Science, 13, 34-51. 
Jowett, S. (2017). Coaching effectiveness: The coach-athlete relationship at its heart. Current Opinion in Psychology, 16, 154-158.

Jowett, S., \& Clark-Carter, D. (2006). Perceptions of empathic accuracy and assumed similarity in the coach-athlete relationship. British Journal of Social Psychology, 45, 617-637.

Jowett, S., \& Cockerill, I. M. (2003). Olympic Medalists' perspective of the athlete-coach relationship. Psychology of Sport and Exercise, 4, 313-331.

Jowett, S., \& Frost, T. (2007). Race/Ethnicity in the all-male coach-athlete relationship: Black footballers' narratives. International Journal of Sport and Exercise Psychology, 5, 255269.

Jowett, S., \& Lavallee, D. (2007). Social psychology in sport. Windsor, ON: Human Kinetics.

Jowett, S., \& Meek, G. (2000). Coach-athlete relationships in married couples: An exploratory content analysis. The Sport Psychologist, 14, 157-175.

Jowett, S., \& Nezlek, J. (2011). Relationship interdependence and satisfaction with important outcomes in coach-athlete dyads. Journal of Social and Personal Relationships, 29, 287 301.

Jowett, S., \& Ntoumanis, N. (2004). The Coach-Athlete Relationship Questionnaire (CART-Q): Development and initial validation. Scandinavian Journal of Medicine and Science in Sports, 14, 245-257.

Jowett, S., Paull, G., \& Pensgaard, A. M. (2005). Coach-athlete relationship. In J. Taylor \& G. S. Wilson (Eds.), Applying sport psychology: Four perspectives (pp. 153-170). Champaign, IL: Human Kinetics. 
Jowett, S., \& Poczwardowski, A. (2007). Understanding the coach-athlete relationship. In S. Jowett \& D. Lavallee (Eds.), Social psychology in sport (pp. 3-14). Champaign, IL: Human Kinetics.

Jowett, S., \& Shanmugam, V. (2016). Relational coaching in sport: Its psychological underpinnings and practical effectiveness. In R. J. Schinke, K. R., McGannon, \& B. Smith (Eds.), Routledge international handbook of sport psychology (pp. 471-484). Abingdon, Oxon: Routledge.

Jowett, S., Shanmugam, V., \& Caccoulis, S. (2012). Collective efficacy as a mediator of the link between interpersonal relationships and athlete satisfaction in team sports. International Journal of Sport and Exercise Psychology, 10, 66-78.

Jowett, S., \& Timson-Katchis, M. (2005). Social networks in sport: Parental influence on the coach-athlete relationship. The Sport Psychologist, 19, 267-287.

Jowett, S., Yang, X. S., Lorimer, S. (2012). The role of personality, empathy, and satisfaction within the context of the coach-athlete relationship. International Journal of Sports Coaching, 6, 3-20.

Kerr, J.H., \& Grange, P. (2009). Athlete-to-athlete verbal aggression: A case study of interpersonal communication among elite Australian footballers. International Journal of Sport Communication, 2, 360-372.

Kim, J., Bloom, G. A., \& Bennie, A. (2016). Intercollegiate coaches' experiences and strategies for coaching first-year athletes. Qualitative Research in Sport, Exercise, and Health, 8, 394-408.

Kimiecik, J., \& Gould, D. (1987). Coaching psychology: The case of James “Doc” Counsilman. The Sport Psychologist, 1, 350-358. 
Laborde, S., Dosseville, F., \& Allen, M. S. (2016). Emotional intelligence in sport and exercise: A systematic review. Scandinavian Journal of Medicine \& Science in Sports, 26, 862874.

Lafrenière, M.-A. K., Jowett, S., Vallerand, R. J., \& Carbonneau, N. (2011). Passion for coaching and the quality of the coach-athlete relationship: The mediating role of coaching behaviors. Psychology of Sport and Exercise, 12, 144-152.

Lafrenière, M.-A. K., Jowett, S., Vallerand, R. J., Donahue, E. G., \& Lorimer, R. (2008). Passion in sport: On the quality of the coach-player relationship. Journal of Sport and Exercise Psychology, 30, 541-560.

Lanzetta, J., \& Englis, B. (1989). Expectations of cooperative and competition and their effects on observers' vicarious emotional responses. Journal of Personality and Social Psychology, 54, 543-554.

Lincoln, Y. S., \& Guba, E. G. (1985). Naturalistic inquiry. Beverly Hills, CA: Sage.

Lorimer, R. (2009). Coaches' satisfaction with their athletic partnerships. International Journal of Coaching Science, 3, 55-64.

Lorimer, R., \& Jowett, S. (2009a). Empathic accuracy in coach-athlete dyads who participate in team and individual sports. Psychology of Sport and Exercise, 10, 152-158.

Lorimer, R., \& Jowett, S. (2009b). Empathic accuracy, meta-perspective, and satisfaction in the coach-athlete relationship. Journal of Applied Sport Psychology, 21, 1-12.

Lorimer, R., \& Jowett, S. (2010). The influence of role and gender in the empathic accuracy of coaches and athletes. Psychology of Sport and Exercise, 11, 206-211. 
Lorimer, R., \& Jowett, S. (2011). Empathic accuracy, shared cognitive focus, and the assumptions of similarity made by coaches and athletes. International Journal of Sport Psychology, 42, 40-54.

Lorimer, R., \& Jowett, S. (2012). Empathetic understanding and accuracy in the coach-athlete relationship. In P. Potrac, W. Gilbert, \& J. Denison (Eds.), Routledge handbook of sports coaching (pp. 321-332). London, UK: Routledge.

Lorimer, R., \& Jowett, S. (2014). Coaches. In A. G. Papaioannou \& D. Hackfort (Eds.), Routledge companion to sport and exercise psychology: Global perspectives and fundamental concepts (pp. 171-186). London: Routledge.

Lyle, J. (2002). Sports coaching concepts: A framework for coaches' behaviour. London: Routledge.

Lyle, J. (2010). Coaches' decision making: A naturalistic decision making analysis. In J. Lyle \& C. Cushion (Eds.), Sports coaching: Professionalisation and practice (pp. 27-42). Edinburgh: Churchill Livingstone Elsevier.

Mallett, C. J. (2005). Self-determination theory: A case study of evidence-based coaching. The Sport Psychologist, 19, 417-429.

Mallett, C. J. (2010). Becoming a high-performance coach: Pathways and communities. In J. Lyle \& C. Cushion (Eds.), Sports coaching: Professionalism and practice (pp. 119-133). London: Elsevier.

Mallet, C. J., \& Lara-Bercial, S. (2016). Serial winning coaches: People, vision, and environment. In M. Raab, P. Wylleman, R. Seiler, A.-M. Elbe, \& A. Hatzigeorgiadis (Eds.), Sport and exercise psychology research: From theory to practice (pp. 289-322). London: Elsevier. 
Martens, R. (1987). Coaches guide to sport psychology: A publication for the American Coaching Effectiveness Program: Level 2 sport science curriculum. Champaign, IL: Human Kinetics.

Mayer, J. D., \& Salovey, P. (1997). What is emotional intelligence? In P. Salovey \& D. Sluyter (Eds.), Emotional development and emotional intelligence: Implications for educators (pp. 3-31). New York: Basic Books.

McGannon, K. R., \& Schweinbenz, A. (2011). Traversing the qualitative-quantitative divide using mixed methods: Some reflections and reconciliations for sport and exercise psychology. Qualitative Research in Sport, Exercise and Health, 3, 370-384.

Mellalieu, S., Shearer, D. A., \& Shearer, C. (2013). A preliminary survey of interpersonal conflict at major games and championships. The Sport Psychologist, 27, 120-129.

Moll, T., Jordet, G., \& Pepping, G.J. (2010). Emotional contagion in soccer penalty shootouts: Celebration of individual success is associated with ultimate team success. Journal of Sports Sciences, 28, 983-992.

Nash, C., \& Collins, D. (2006). Tacit knowledge in expert coaching: Science or art? Quest, 58, $465-477$.

Nideffer, R. M. (1986). Concentration and attention control training. In J. M. Williams (Ed.), Applied sport psychology (pp. 257-270). Mountain View, CA: Mayfield.

Niven, K., Totterdell, P., \& Holman, D. (2007). Changing moods and influencing people: The use and effects of emotional influence behaviours at HMP Grendon. Prison Service Journal, 173, 39-45.

Olusoga, P., Maynard, I., Hays, K., \& Butt, J. (2012). Coaching under pressure: A study of Olympic coaches. Journal of Sport Sciences, 30, 229-239. 
Olympiou, A., Jowett, S., \& Duda, J. L. (2008). The psychological interface between the coach-created motivational climate and the coach-athlete relationship in team sports. The Sport Psychologist, 22, 423-438.

O’Neill, D. H. (2008). Injury contagion in alpine ski racing: The effects of injury on teammates' performance. Journal of Clinical Sport Psychology, 2, 278-292.

Patton, M. (1990). Qualitative evaluation and research methods. London: Sage.

Philippe, R. A., \& Seiler, R. (2006). Closeness, co-orientation and complementarity in coachathlete relationships: What male swimmers say about their male coaches. Psychology of sport and exercise, 7, 159-171.

Poczwardowski, A., Barott, J. E., \& Henschen, K. P. (2002). The athlete and coach: Their relationship and its meaning. Results of an interpretive study. International journal of sport psychology, 33, 116-140.

Poucher, Z. A., Tamminen, K. A., Caron, J. G., \& Sweet, S. N. (in press). Thinking through and designing qualitative research studies: A focused mapping review of 30 years of qualitative research in sport psychology. International Review of Sport and Exercise Psychology, 1-24.

Rhind, D. J., \& Jowett, S. (2012). Development of the coach-athlete relationship maintenance questionnaire (CARM-Q). International Journal of Sports Science \& Coaching, 7, 121137.

Rhind, D. J. A., Jowett, S., \& Yang, S. X. (2012). A comparison of athletes' perceptions of the coach-athlete relationship in team and individual sports. Journal of Sport Behavior, $35,433-452$. 
Ritchie, D., \& Allen, J. (2015). 'Let them get on with it': Coaches' perceptions of their roles and coaching practices during Olympic and Paralympic games. International Sport Coaching Journal, 2, 108-124.

Ronglan, L. T. (2007). Building and communicating collective efficacy: A season-long in-depth study of an elite sport team. The Sport Psychologist, 21, 78-93.

Rubin, H. J., \& Rubin, I. S. (2012). Qualitative interviewing: The art of hearing data. Thousand Oaks, CA: Sage.

Salminen, S., \& Liukkonen, J. (1996). Coach-athlete relationship and coaching behaviour in training sessions. International Journal of Sport Psychology, 27, 59-67.

Schempp, P. G., \& McCullick, B. (2010). Coaches’ expertise. In J. Lyle \& C. Cushion (Eds.), Sports coaching: Professionalisation and practice (pp. 221-231). Edinburgh: Churchill Livingstone Elsevier.

Schön, D.A. (1983). The reflective practitioner: How professionals think in action. New York: Basic Books.

Schoenewolf, G. (1990). Emotional contagion: Behavioural induction in individuals and groups. Modern Psychoanalysis, 15, 49-61.

Schwandt, T. A. (2001). Dictionary of qualitative inquiry (2nd ed.). Thousand Oaks, CA: Sage.

Shapcott, K. M., Bloom, G. A., \& Loughead, T. M. (2007). An initial exploration of the factors influencing aggressive and assertive intentions of women ice hockey players. International Journal of Sport Psychology, 38, 145-162.

Sillars, A. L. (1985). Interpersonal perception in relationships. In W. Ickes (Ed.), Compatible and incompatible relationships (pp. 277-305). New York: Springer-Verlag. 
Sillars, A. L., \& Scott, M. D. (1983). Interpersonal perception between intimates: An integrative review. Human Communication Research, 10, 153-176.

Smith, M., \& Cushion, C. J. (2006). An investigation of the in-game behaviours of professional, top-level youth soccer coaches. Journal of Sports Sciences, 24, 355-366.

Smith, B., \& McGannon, K. R. (2018). Developing rigor in qualitative research: Problems and opportunities within sport and exercise psychology. International Review of Sport and Exercise Psychology, 11, 101-121.

Smith, B., \& Sparkes, A. C. (2016). Interviews: Qualitative interviewing in the sport and exercise sciences. In B. Smith \& A. C. Sparkes (Eds.), Routledge handbook of qualitative research in sport and exercise (pp. 103-123). New York, NY: Routledge.

Smith, B., Sparkes, A., \& Caddick, N. (2014). Judging qualitative research. In L. Nelson, R. Groom, \& P. Potrac (Eds.), Research methods in sports coaching (pp. 192-201). New York: Routledge.

Sparkes, A. C., \& Smith, B. (2014). Qualitative research methods in sport, exercise and health: From process to product. London: Routledge.

Stein, J., Bloom, G. A., \& Sabiston, C. M. (2012). Influence of perceived and preferred coach feedback on youth athletes' perceptions of team motivational climate. Psychology of Sport and Exercise, 13, 484-490.

Thelwell, R. C., Wagstaff, C. R. D., Rayner, A., Chapman, M., \& Barker, J. (2017). Exploring athletes' perceptions of coach stress in elite sport environments. Journal of Sport Sciences, 35, 44-55. 
Thomas, G., \& Fletcher, G. (2003). Mind-reading accuracy in intimate relationships: Assessing the roles of the relationship, the target, and the judge. Journal of Personality and Social Psychology, 85, 1079-1094.

Totterdell, P. (2000). Catching moods and hitting runs: Mood linkage and subjective performance in professional sport teams. Journal of Applied Psychology, 85, 848-859.

Trzaskoma-Bicserdy, G., Bognar, J., Revesz, L., \& Geczi, G. (2007). The coach-athlete relationship in successful Hungarian individual sports. International Journal of Sports Science \& Coaching, 2, 485-495.

Uphill, M. A., McCarthy, P. J., Jones, M. V. (2009). Getting a grip on emotion regulation in sport: Conceptual foundations and practical application. In S. D. Mellalieu \& S. Hanton (Eds.), Advances in applied sport psychology (pp. 162-194). Oxon: Routledge.

Urquhart, D. A., Bloom, G. A., \& Loughead, T. M. (in press). The Development, articulation, and implementation of a coaching vision of multiple championship-winning university ice hockey coaches. International Sport Coaching Journal.

Vallée, C. N., \& Bloom, G. A. (2005). Building a successful university program: Key and common elements of expert coaches. Journal of Applied Sport Psychology, 17, 179-196.

Vargas, T. M., \& Short, S. E. (2011). Athletes' perceptions of the psychological, emotional, and performance effects of coaches' pre-game speeches. International Journal of Coaching Science, 5, 27-43.

Vargas-Tonsing, T. M., \& Guan, J. (2007). Athletes’ preferences for informational and emotional pre-game speech content. International Journal of Sports Science \& Coaching, $2,171-180$. 
Wachsmuth, S., Jowett, S., \& Harwood, C. G. (2017). Conflict among athletes and their coaches: What is the theory and research so far? International Review of Sport and Exercise Psychology, 10, 84-107.

Wrisberg, C. A. (1990). An interview with Pat head Summitt. The Sport Psychologist, 4, 180191.

Yang, S. X., Jowett, S., \& Chan, D. K. C. (2015). Effects of big-five personality traits on the quality of relationship and satisfaction in coach-athlete dyads. Scandinavian Journal of Medicine and Science in Sports, 25, 568-580.

Yin, R. K. (2009). Case study research: Design and method (4th ed.). Thousand Oaks, CA: Sage. 


\section{Appendix A \\ Recruitment Script}

Dear

My name is Siobhan Henderson and I am currently working towards a Master of Arts degree in sport psychology at McGill University under the supervision of Dr. Gordon Bloom. We would like to invite you to participate in our study examining effective coaching behaviours in competition. We are contacting you based on a set of criteria highlighting your athletic success and achievement at the international level.

If you choose to participate in this study, you will be asked to partake in a face-to-face interview that would last approximately one hour in a location of your choice. If more information is required, a follow up interview may occur. The questions would revolve around your experiences with your coaches.

The McGill University Ethics Board has reviewed and accepted this study for its adherence to ethical guidelines. All of the information provided will be confidential and the responses will only be analyzed by myself, my supervisor Dr. Gordon Bloom, and the research team. The interpretations and results will be sent back to you after the interview to ensure for accuracy and to allow you the opportunity to clarify any of your answers.

Should you have any questions concerning this study, please contact my myself or my supervisor using the information provided at the bottom of the page. The McGill Sport Psychology Research Laboratory has a history of producing influential research on sport coaching and leadership. Please visit our website if you would like to learn more about our research: http://sportpsych.mcgill.ca

Thank you for considering participating in this research project, and I look forward to hearing from you.

Sincerely,

Siobhan Henderson

Siobhan Henderson, B.Sc.

Master's Candidate, Sport Psychology

Dept. of Kinesiology \& PE

McGill University, Montreal

siobhan.henderson@mail.mcgill.ca
Gordon A. Bloom, Ph. D.

Full Professor

Dept. of Kinesiology \& PE

McGill University, Montreal

gordon.bloom@mcgill.ca 


\section{Appendix B \\ Informed Consent Form}

This study is in partial fulfillment of the requirements for the degree of Master of Arts for Siobhan Henderson, a current graduate student in sport psychology in the Department of Kinesiology and Physical Education at McGill University. You are invited to participate in the research study entitled: "Desired coaching interactions and behaviours of elite individual sport athletes during competition". If you choose to participate in this study, you will be asked to partake in a 60 minute, audio recorded interview, without compensation. If more information is required, an additional follow-up interview may be requested either in person, over the telephone, or virtually over Skype. During the interview, you will be asked questions regarding your experiences with coaches and desired coaching behaviours.

At the end of the interview, you will have the opportunity to ask any questions or make any additional comments that were not discussed throughout the interview. You will receive a typed transcript of the interview, where you may edit it at your own discretion. You will also receive a copy of the results and conclusions of the study prior to publication. Your identity will remain confidential at all times and the primary researcher, Siobhan Henderson, and the faculty supervisor, Dr. Gordon Bloom, will be the only individuals with access to a copy of the responses. All of the data, including the audio recorded copy of the interview and the consent form will be stored in an encrypted folder on a password-protected computer for seven years. Any paper copies of notes will be converted into digital files and destroyed at the end of the study. The information gathered from the study will be used solely for conference presentations and journal article publications and your confidentiality will be maintained and respected throughout the entirety of the process. Your participation in this study is voluntary and not mandatory, therefore you have the ability to refuse to answer any questions without penalty and if you choose to withdraw from the study, all information attained up until that point will be destroyed.

After reading the above statements you can now provide consent to voluntarily agree to participate in this research study based on the terms outlined in this consent form. You will be provided with a signed copy of this consent form. If you have any additional questions or concerns regarding your rights and welfare as a participant in this research study, please feel free to contact lynda.mcneil@mcgill.ca or at 514-3986831. Please sign below if you agree to participate:

Signature

Researcher's Signature
Date

Date

I agree (CHECK YES $\square$ OR NO $\square$ ) to the audio recording of the interviews with the understanding that these recordings will be used solely for the purpose of transcribing these sessions.

Siobhan Henderson, B.Sc.

Master's Candidate, Sport Psychology

Dept. of Kinesiology \& PE

McGill University, Montreal

siobhan.henderson@mail.mcgill.ca
Gordon A. Bloom, Ph.D.

Full Professor

Dept. of Kinesiology \& PE

McGill University, Montreal

gordon.bloom@mcgill.ca 


\section{Appendix C \\ Semi-Structured Interview Guide}

Pre-Interview Routine

- Introduction of the researcher

- Overview of the study

Opening Questions (brief answers)

1. Please briefly describe your athletic career, including your greatest accomplishments.

2. Please provide an overview of the coaches you have had throughout your career?

a. Gender coaching differences?

b. Age differences?

c. Culture?

d. Language?

e. History of coaches before your current coach?

$f$. Length of time with current coach?

g. How much input have you had choosing your coaches?

3. Please provide a rationale for which coach(es) have helped you the most throughout your career.

Key Questions

4. From the moment you arrive at the competition site to the moment that you complete your first dive, please describe all of the interactions with your coach.

a. What are the coach's routines and responsibilities?

$b$. When and how often do you and the coach communicate?

c. What does the coach say? And how does he/she say it?

d. What do you find most helpful from your coach during this time?

$e$. What do you find the least helpful from your coach during this time?

f. Emotions of the coach?

5. From the moment that you have completed your first dive of the day to the moment you have completed your last dive, please describe the interactions with your coach.

a. What are the coach's routines and responsibilities?

b. When and how often do you and the coach communicate?

c. What does the coach say? And how does he/she say it?

d. What do you find most helpful from your coach during this time?

$e$. What do you find the least helpful from your coach during this time?

$f$. Are there any changes in the interactions with the coach based on the round?

$g$. Are there any changes in the interactions with the coach based on your scorelperformance?

h. Emotions of the coach? 
6. How does the importance of a competition and/or the significance of a dive (e.g., level of difficulty) influence the coach's interactions with you?

a. Emotions of the coach?

b. Amount offeedback/communication

c. Frequency of feedback/communication

7. Recounting your best and worst elite competitive experiences, can you recall what your coach did or said to you at this time that might have impacted your performance?

8. Throughout your career, in what ways have the relationship with your coach been a contributing factor in your diving success?

a. How does the length of the relationship influence its quality?

b. Please tell me about the value of sharing common goals and expectations in your relationship with your coach.

c. Please tell me about the value of trust and respect in your relationship with your coach.

d. Please tell me whether friendliness is important in your relationship with your coach.

e. If so, how do you communicate to your coach how you would like to be coached in competition?

9. Suppose you are providing recommendations for coach educators working with individual sport coaches in the context of competition. In the form of a list of do's and don'ts, what would your list include?

\section{Concluding Questions}

10. Is there anything you would like to add that we have not discussed today?

11. Do you have any comments or questions?

Probes: Key phrases to stimulate reflection

- Can you expand on that?

- Can you clarify that?

- That's interesting, tell me more about that.

- Could you please tell me more about this? 
Table 1. Codes, themes, and overarching themes from data analysis

\begin{tabular}{|c|c|c|}
\hline CODES & THEMES & $\begin{array}{c}\text { OVERARCHING } \\
\text { THEMES } \\
\end{array}$ \\
\hline $\begin{array}{l}\text { 1. Athlete enjoyment (4) } \\
\text { 2. Athlete evolution (7) } \\
\text { 3. Athlete expectations (5) } \\
\text { 4. Athlete superstitions (2) } \\
\text { 5. Athlete work ethic (4) } \\
\text { 6. Career highlights (8) } \\
\text { 7. History of coaches (10) } \\
\text { 1. Building character (3) } \\
\text { 2. Coach demands (11) } \\
\text { 3. Coach expectations (3) } \\
\text { 4. Coach experience (3) } \\
\text { 5. Coach passion (2) } \\
\text { 6. Emotions of coach (19) }\end{array}$ & $\begin{array}{l}\text { 1) Athlete experiences and } \\
\text { characteristics ( } 40) \text { : Experiences } \\
\text { and attributes of the athlete. }\end{array}$ & $\begin{array}{l}\text { 1) Background and } \\
\text { characteristics }(81) \text { : } \\
\text { Experiences and } \\
\text { characteristics of athletes } \\
\text { and coaches contributing } \\
\text { to their behaviours and } \\
\text { success. }\end{array}$ \\
\hline $\begin{array}{l}\text { 1. Coach caring (8) } \\
\text { 2. Coach trust (7) } \\
\text { 3. Coach understanding athlete } \\
\text { (15) } \\
\text { 4. Friendliness (9) } \\
\text { 5. Relationship length (6) } \\
\text { 6. Coach support (8) } \\
\\
\text { 1. Coach negativity (40) } \\
\text { 2. Disappointing coach (7) } \\
\text { 3. Emotions of coach - negative } \\
\text { 4. Fear of coach (2) }\end{array}$ & $\begin{array}{l}\text { 3) Coach-athlete closeness (53): } \\
\text { Aspects of the relationship between } \\
\text { the coach and athlete reflecting } \\
\text { their appreciation of the partnership } \\
\text { and how it positively influenced } \\
\text { their interactions. } \\
\text { 4) Coach-athlete challenges ( } 61) \text { : } \\
\text { Coach behaviours that distract } \\
\text { athletes from focusing on the task at } \\
\text { hand. }\end{array}$ & $\begin{array}{l}\text { 2) Coach-athlete } \\
\text { relationship (114): } \\
\text { Positive and negative } \\
\text { factors of the relationship } \\
\text { influencing all facets of } \\
\text { their partnership. }\end{array}$ \\
\hline
\end{tabular}


1. Performance goals (10)

2. Coach goal setting (6)

3. On same page (25)

1. Coach communication (23)

2. Coach feedback (18)

3. Coach instruction (25)

4. Key words (11)

1. Athlete flow state (5)

2. Calming down athlete (5)

3. Coach confidence (21)

4. Coach motivation (11)

5. Coach positivity (11)

1. Athlete routines - Precompetition (11)

2. Athlete routines - Incompetition (24)

3. Athlete routines - Postcompetition (2)

4. Athlete stress (9)

5. Performance pressure (12)

6. Coach adaptation (17)

7. Game-day coach support (8)
5) Coach-athlete goals (41):

Processes between coach and athletes that relate to the creation and establishment of goals.

6) Communication (77): Aspects related to what and how a coach talks to an athlete in competition.

7) Coach influence on athlete readiness (53): Coach behaviours influencing athlete regulation and ability to perform.

8) Game-day patterns (83): Elements related to how athletes deal with the physical and mental aspects on game-day and how these are influenced by coaching behaviours.
3) Coaching strategies and behaviours (254):

Strategies and behaviours used by coaches that influence how their athletes cope with and perform during competition 